\title{
CLIMATE JUSTICE: BALANCING THE RIGHT TO DEVELOP AND THE NORM OF SUSTAINABILITY
}

By

Ushana Jayasuriya

A thesis submitted to the Victoria University of Wellington in fulfilment of the requirements for the degree of

Master of Arts

In Philosophy

Victoria University of Wellington 


\section{Acknowledgements}

I would like to express my gratitude to all those who helped me during the course of my research, especially my supervisor, Dr. Ramon Das. His guidance and constructive critiques were invaluable in the production of this research work.

I also thank the School of History, Philosophy, Political Science and International Relations, especially the Philosophy department for providing space, facilities, and administrative support.

This research was made possible through funding provided by Victoria University of Wellington in the form of the Master's by Thesis Fees Scholarship and; Graduate Women Wellington through the Master's by Thesis Scholarship.

Finally, I wish to thank my family and my partner for their support and encouragement throughout my study. 


\begin{abstract}
Climate change presents a global problem that requires collective action. Distributing obligations in relation to this has proven problematic, especially in light of the divide between wealthy and developed states compared to poor and developing states. The norm of sustainability requires states to continue to protect and promote sustainable actions. This comes into direct conflict with the right to develop when considering how to mitigate climate change. The right to develop requires the use of limited resources now, whereas the norm of sustainability argues that these resources must be protected for both environmental protection and intergenerational justice. Intragenerational justice requires us to consider whether actions that protect the future may be causing greater injustice within the present generation. In this thesis, I discuss the important potential distribution principles, with considerations of historic responsibility, uncertainty, and the ability to pay principles. I then use this foundation to explore how a right to develop can fit within the balance of intergenerational and intragenerational justice. I also include the context of non-ideal theory as a means of making the discussion more relevant to the realworld situation we find ourselves in, with the partial and noncompliance of many states. I conclude that, within the context of nonideal theory, there is a right to develop but currently it ought to be limited to a basic needs threshold if we wish to justly distribute obligations between and across generations.
\end{abstract}




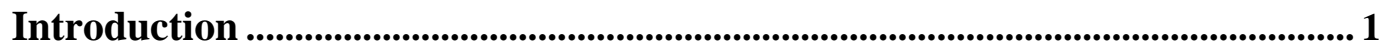

Chapter One: Distribution of Obligations ............................................................................. 7

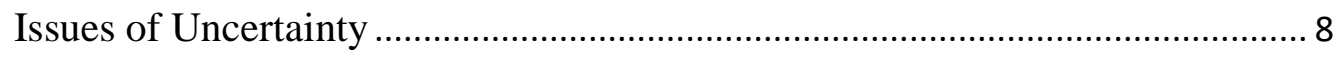

Historic Emissions and Climate Debt................................................................ 10

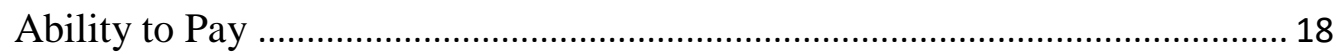

Establishing a Right to Develop...................................................................... 24

Chapter Two: Climate Justice and Non-Ideal Theory .......................................... 26

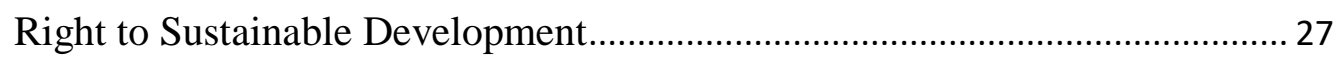

Assumption of compliance with the demands of justice ................................... 33

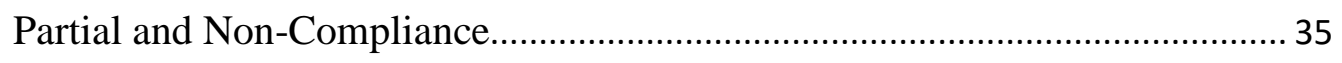

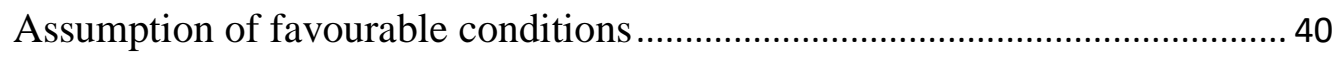

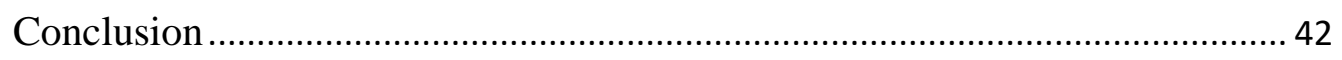

Chapter Three: Intergenerational Equity ..................................................................... 44

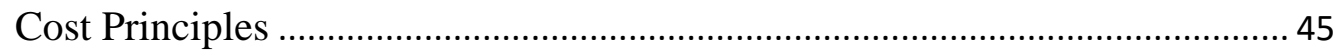

Determining the Social Discount Rate …....................................................... 50

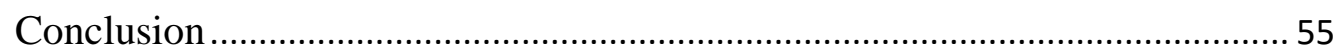

Chapter Four: Intra-Generational Justice ...................................................................... 57

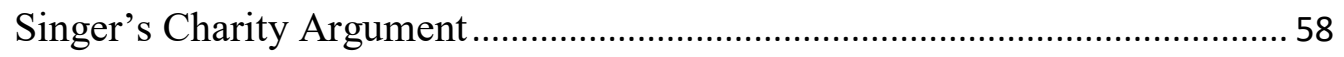

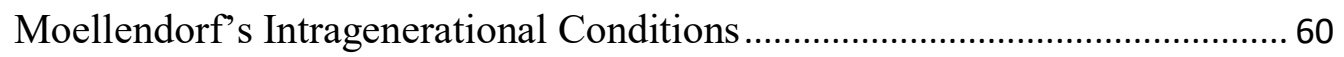

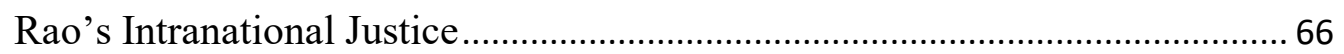

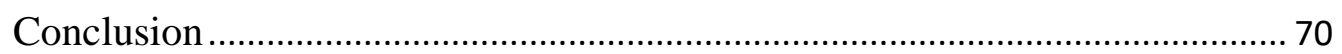

Chapter Five: Potential Solutions and Future Leadership .............................. 73

Leadership in Climate Change Agreements..................................................... 74

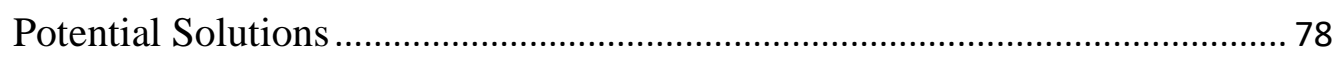

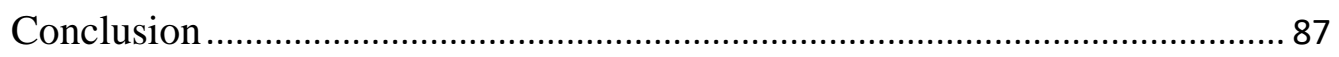

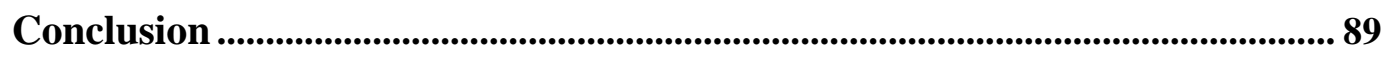

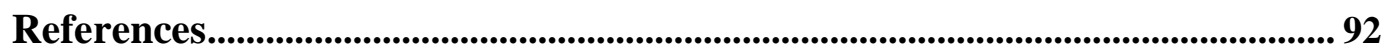




\section{Introduction}

Climate change is a topic of growing interest in international affairs, as there is constant concern yet little action in response to a growing threat. There are many challenges within climate change and I wish to clarify where my discussion in the topic lies. Climate change is a broad and multifaceted topic, however, in this thesis I will not explore the scientific aspect of climate change but instead focus on some of the ethical considerations around climate obligations. I will therefore continue on the assumption that climate change is a real threat to all people, and that there is still action that can be taken in order to combat it.

In this thesis, I argue for a limited right to develop balanced with the norm of sustainability. It is essential that these two elements are discussed and thought of together, as in isolation the reality of the implications of each idea cannot be fully understood. In many discussions the right to develop is seen as a given, it is something that ought to happen. I argue that there must be significant limitations to this right in order to have a just distribution of obligations across and between generations. However, the norm of sustainability must still allow for this basic right to develop to adhere to the same obligations of justice.

In Chapter One: Distribution of Obligations, I outline some of the key principles of distributive justice considered in climate agreements. I explore the issue of historic emissions and climate debt, including the principles of polluter pays and beneficiary pays, and the ability to pay principle. I shall argue that the historic or backward-looking principles are harder to justify. This is due to the uncertainty that surrounds the exact contribution of countries from historic emissions, as well as their culpability due to ignorance about the effects of carbon emissions at the time. The ability to pay principle, on the other hand, does not look to place blame and instead focuses on who would 
best be able to afford the costs of mitigating climate change. Some criticise this approach due to the lack of accountability for those who have contributed more to the problem. However, I argue that the ability to pay principle appears to be the best suited to climate agreements, especially when we seek to balance the right to develop with climate obligations. This chapter therefore establishes the foundation of the argument for a right to develop. In particular, I support Darrel Moellendorf's formulation of a right to sustainable development, which argues for this right to meet at least a basic needs threshold (Moellendorf, 2014: 124). Although this is not as far as many least-developed and developing countries may desire, it is a compromise to balance the right with the norm of sustainability. I conclude this chapter by suggesting that there ought to be a right to develop, which should be reflected in the distribution principles used for climate change mitigation.

Chapter Two: Climate Justice and Non-Ideal Theory, considers how non-ideal theory may influence the distribution of obligations, especially in relation to the right to develop in light of realities of the current international situation. I outline Laura Valentini's formulation of non-ideal theory, based on that by Rawls (Valentini, 2012: 655). Using the ideal assumptions that she identifies, I argue that the first assumption, that all states will comply with the demands of justice, casts doubt on the ability to allow an unlimited right to develop. I go on to consider David Miller's proposals of how states react to partial or non-compliance and argue that the reality of partial compliance significantly hinders the climate change mitigation agenda (Miller, 2011: 233). ${ }^{1}$ I also discuss whether there are different implications depending on which state (or which category of state) has failed to meet its obligations. I determine that there are different implications as the reasons that lead to the lack of compliance are significant in

${ }^{1}$ We already have the clear case of the United States of America withdrawing from the Paris Agreement 2015, an agreement that even under full compliance would not reach its goal. 
evaluating the reasonableness of the state's actions. Essentially, it is less acceptable that some states fail to meet their obligations due to prioritising profits, compared to other states not meeting their obligations due to the pressure of raising people out of poverty. However, the overall impact of partial and non-compliance means we must alter our conception of what a reasonable solution may be. Though we might wish to allow for a greater right to develop, the application of non-ideal theory illustrates that it is perhaps an unlikely allowance to make in the current context if we wish to balance this right with the norm of sustainability.

In Chapter Three: Intergenerational Justice, I extend the argument against an unlimited right to develop through intergenerational considerations. In this chapter I discuss three cost principles outlined by Moellendorf for different scenarios that may arise for future generations (Moellendorf, 2009(b): 207). These are based on the current or likely near-future conditions for the least-developed and developing nations of today. I then discuss some arguments of Simon Caney's regarding social discount rates (Caney, 2014: 321). These arguments raise questions about whether a generation can exercise time preference actions. Time preference is the idea that preferential treatment can be given to one's own generation, for instance through discounting the weighting of future generations in considerations made today. In all the options outlined by Caney, urgent action on climate change mitigation is still needed. Central to Caney's proposals is the assumption that future generations will likely be wealthier than we are. Although this may be a legitimate assumption, I argue that it is doubtful whether we can assign greater obligations to future generations on this basis. However, Caney and Moellendorf agree that some deferral to future generations can be justified, especially in relation to the right to develop. By allowing for some development it is likely that there will be greater equity in the future and therefore a greater ability to pay for the costs of climate change mitigation. This chapter further justifies the need to limit 
development, while also recognising the tensions that may arise from promoting the rights of future generations while current generations suffer.

Chapter Four: Intragenerational Justice, brings together many of the ideas from the previous sections, while also examining relevant justice considerations within the current generation. I aim to evaluate some intragenerational considerations that ought to be incorporated into the distribution of obligations. The actions around poverty reduction we make today will have significant impacts on the equality and equity of future generations. Furthermore, these considerations ought to influence the distribution of obligations as we seek justice within our generation and within each nation. In this chapter I discuss Moellendorf's three scenarios for poverty alleviation going into the future (Moellendorf, 2009(b): 206). This is an important element in determining which decisions around the distribution of obligations are most justifiable. This also takes into account the previous chapter's discussion around the intergenerational considerations that may limit the right to develop. However, in this chapter I raise more discussions in support of the right to develop as a mechanism of reducing overall emissions and creating greater equality across and between generations. In this section, I discuss the opportunity cost argument for limiting the right to develop, which strongly favours the Moellendorf formulation of the right to sustainable development (Moellendorf, 2009(b): 211). Using these arguments from Moellendorf, I propose that for true intergenerational justice there must be consideration of the current generation, whereas often intergenerational justice only focuses on the welfare of future generations. In this chapter I also discuss the work of Narasimha Rao, who raises intranational justice as another significant consideration (Rao, 2014). Rao discusses how differentiating at a state level may no longer be appropriate given the circumstances of large emerging economies such as China and India (Rao: 135). When distributing obligations and resources, it is important to consider how a state 
manages inequality within the state, rather than purely focusing on absolute numbers. This also relates to the discussion raised in previous chapters about the appropriate means of distribution, which could be challenged by this idea of intranational justice. Rao argues that there ought to be a more targeted method of distributing obligations to reach a fair outcome (134). This perhaps calls for a different approach to climate change obligations.

Chapter Five explores alternatives to the previous and current approaches to climate change mitigation obligations. I begin the chapter by discussing Henry Shue's critique on the lack of leadership in international climate negotiations (Shue, 2011). This lack of leadership increases the tension and reduces the chances of a successful agreement, especially with the different priorities of developed and developing countries. I discuss how in recent years the competition for leadership has become more desirable for states, particularly the emerging economies who recognise the potential benefits of positive climate action. I then discuss the current Emissions Trading Scheme, its disadvantages and potential approaches that may be more appropriate in the climate change context. This leads to my discussion of combining outcome responsibility and the ability to pay principle as a potential solution to the current approach to climate change agreements. By removing blame and focusing more on responsibility and ability, this approach can cover many of the important considerations of distributive justice. It will not overly burden any state but would allow for a right to develop that recognises the changing position of states in the international community. Those who are able to contribute to climate change mitigation ought to do so in order to protect the right to develop for the current generation, especially to the minimum standard of a basic needs threshold, and maintain the norm of sustainability that will be essential for our just obligations to future generations. 
The right to develop to a basic needs threshold is an obligation for the present generation, but should also be a consideration for future generations. On the other hand, there are undeniable obligations to future generations and forcing obligations on them that they have not agreed to is questionable. There must be a balance achieved that allows development, but not at the cost of serious environmental degradation. Ultimately, we ought to protect the environment that we depend on, and this must be considered in any discussion of how to distribute obligations that respect the right to develop and maintain the norm of sustainability. 


\section{Chapter One:}

\section{Distribution of Obligations}

This chapter will discuss the key distribution principles used in climate agreements that are relevant to the developed-developing distinction. It will look at the justifications for these principles and the advantages and disadvantages of each. This will be the foundation for the discussion as to why there ought to be a right to develop.

A central element of this thesis concerns the initial distribution of responsibilities and obligations in climate negotiations. The expression "common but differentiated responsibilities" is referred to in the Kyoto Protocol which outlines the obligations of each agreeing nation. The intention behind differentiated responsibilities is to acknowledge the conflict between climate change mitigation with the right to develop. The international community faces many challenges to gaining agreement in climate action. In order to counter this, certain perceived inequalities must be addressed. The inequality that I will focus on is that between developed and developing countries, as reflected in the Annex 1 and non-Annex distinction from the Kyoto Protocol. This distinction is important as it was used to identify those countries who needed development (Annex 1) and those that did not. The distinction has not been updated to address the current position of countries and has therefore been a source of some conflict over which states can argue for lesser duties due to the right to develop.

Differentiated responsibilities aim to include developing nations in a way that allows them to develop, by limiting or reducing their obligations, while still respecting the requirement for collective action against climate change. Differentiated responsibilities also attempts to address the perceived inequalities through historic carbon emissions and other environmental damage caused by developed nations in the process of development. 
Developing nations argue they too have the right to use resources to develop, however, with modern knowledge and acknowledgement of climate damage and the potential of a tipping point from which there is no return. I shall argue efforts to curb resource exploitation must be made on a scale that limits the available resources for developing countries to aid their development. I use Moellendorf's definition of a sustainable right to develop to promote this limited right that I will argue throughout this thesis is compatible with the overall goal of climate change mitigation. There will still be some conflict with the other significant principle of this thesis, the norm of sustainability. Sustainability requires promoting only activities that are sustainable and do not exploit the resources that have been exploited before, especially harmful fossil fuels that cause significant emissions. However, as I will argue throughout this thesis, we ought to afford the least-developed and other developing nations their right to sustainable development, and the norm of sustainability, though important, can only be secondary to this right.

When determining the differing obligations of developed and developing states in climate negotiations there are several elements that need to be evaluated. This chapter will explore the issues of: uncertainty; historic emissions; climate debt; and the ability to pay. I conclude that the ability to pay principle is the most favourable for a fair distribution, for both certainty and burden sharing. The ability to pay principle is the only principle not affected by the uncertainty that often plagues climate change discussions, especially in relation to distribution of obligations. Furthermore, the principle does not place a burden that is too heavy for any country to bear or look to place blame.

\section{Issues of Uncertainty}

There are two interrelated elements of uncertainty that play into climate negotiations. The first relates to climate deniers, the second to measuring the impact of past emissions. There are varying reports 
as to the impact of human activity on climate change, however, there seems to be a strong body of evidence to suggest that there are natural processes that are being exacerbated by human activity. Therefore, though we may dismiss climate change deniers as uninformed or selfinterested, there are legitimate questions about what level of involvement developed countries have truly had on the environmental change that is occurring. If we cannot accurately, or relativelyaccurately, determine the impact of previous emissions then differentiated duties may be undermined. It becomes much more difficult to justify imposing stricter obligations on developed nations based on the impact of previous emissions. There will obviously be opportunity to impose some higher, or more stringent, obligation through the understanding that emissions have definitely accelerated the process, however, not to the extent that we currently differentiate between developed and developing states.

The issue of uncertainty raises questions as to regarding the allocation of obligations when the true impact of past actions is in doubt, and therefore responsibility or accountability of nations for previous emissions. Developed states would feel that they should not be bearing more than their share of the burden. It would not be fair and just to allocate more of the burden to developed nations because they contributed the emissions that resulted in some of the climate change events that happen today. However, it would also be unfair to place this burden on developing states who have not contributed to the problem to the same extent as the developed states. Perhaps, the underlying natural process of climate change would need to be a burden shared by all. One could argue that there may have been a natural process through which we would have seen some of the effects of climate change, however, the effects would have been less than the catastrophic effects that are projected to occur if we do not take action now. The natural process may need to be accounted for through some other means, while the impact of human activity ought to be addressed by those responsible. Either way, catastrophic climate 
change can be seen as a result of human emissions that have exacerbated the natural climate cycle.

However, uncertainty remains, and this is an important element in the conflict at climate negotiations as nations are not willing to take on more than their "fair share" of the burden. Determining the exact impact of a nation's past emissions on climate change would be a time-consuming, if not impossible, task. In creating differentiated responsibilities, ideally the most salient feature should be the extent to which nations have contributed to climate change as a proportion relative to all other contributors, excluding the natural process. There is enough science to suggest that even though there is a natural process, we are accelerating it to a point where there will be no time available for adaption. Though it may be difficult to determine the exact extent of contributions to the problem, some form of distribution which acknowledges the relative difference between developed and developing nations would create a fairer and more just distribution.

\section{$\underline{\text { Historic Emissions and Climate Debt }}$}

Historic emissions may be hard to determine with certainty. However, to distribute obligations fairly, climate negotiations have often included considerations of historic emissions. In relation to future agreements or the fairest method of attributing historic emissions, perhaps the focus should shift to acknowledging a contribution to emissions, without assigning particular levels of blame. This would remove some of the challenges arising from uncertainty, while still acknowledging and addressing the contribution of developed states to the problem. Removing blame would also promote cooperation, rather than create defensive behaviour, with the focus of discussions being around how to help distribute the burdens rather than fingerpointing to figure out who caused which part of the problem. The developed-developing distinction can then be seen as a distribution of duties according to historic development. 
Climate debt raises many of the same considerations, as it is the idea that there is a debt that must be paid. Pickering and Barry suggest the moral element of climate debt is the idea that "Countries that have emitted more than their fair share of the Earth's capacity to safely absorb emissions have moral responsibilities towards low-emitting countries and those vulnerable to the impacts of climate change." (Pickering and Barry, 2012: 670). The moral grounding of this claim rests on the idea of the global commons which is often assumed and widely accepted (671). The idea of a global commons creates moral responsibilities around fair use (671). This can only work when considered on a state level, and similar to the above, if it is based on some form of outcome responsibility. Outcome responsibility is the idea that parties should be jointly responsible for their involvement in activities that produced the outcome. Outcome responsibility does not attribute blame, but focuses instead on righting the wrong that was a consequence of actions by the party in question (Miller, 2004: 246). I will discuss outcome responsibility in more detail in Chapter Five, where I examine potential solutions.

Historic emissions are reflected in principles such as "polluter pays" and "beneficiary pays" which account for contributions to a problem and the responsibility to remedy the problem. These are contrasted by principles such as the "ability to pay principle" which takes a no-fault approach to allocating responsibility (Shue, 2014: 189). Climate negotiations often have elements of both approaches in order to reach agreement. It is hard for developing nations, or nations that have developed but not through the same emissions intensive methods, to agree to share the burden when it appears as though other nations have benefited and done the damage. On the other hand, it is hard for developed countries to agree to take on greater obligations in the face of uncertainty. Also, countries that have recently become large emitters may be able to develop further due to lower obligations being imposed on them. A compromise between these principles allows for developed nations to take on some additional burden compared to the 
developing states, while also recognising the importance of the ability to pay principle in fairly distributing the burdens.

i. Polluter Pays Principle

The polluter pays principle in relation to differentiated responsibilities suggests that if different states contributed to different extents to the causing of climate change, they ought to have different levels of responsibility (Roser and Seidel, 2017: 118). The principle demands states take responsibility for their actions. This is one of the "historical" principles of distribution, as the distribution of costs is dependent on what happened in the past (118). Dominic Roser and Christian Seidel suggest that those with higher past emissions should have greater disadvantages in relation to the sharing of the costs of coping with climate change, which is supported by the United Nations Framework Convention on Climate Change's (UNFCCC) moral implications of differentiated responsibility (118).

There are two versions of the principle that have different moral implications and chances of success.

1. Someone takes more than their fair share and in addition harms others. (119).

In this instance, the polluter pays principle will specify who must rectify the damage.

2. Someone takes more than their fair share and there is no longer enough to spread equally. (119).

In this instance, the polluter pays principle specifies how the remaining benefits should be distributed among the perpetrators and others involved. (119).

The first reading of this principle focusses on the burden of adaption funds and compensation. Roser and Seidel suggest the costs of adaptation can be considered as "putting one's moral house in order." In climate change this means reducing vulnerability to climate 
damage through contributions to adaption funds or, at least, compensating those who were harmed. However, there can be harm without unfairness and unfairness without harm and therefore this reading is difficult to apply in such uncertain circumstances. (Roser and Seidel: 119-120).

The second reading addresses the distribution of remaining emissions, particularly, the distribution of costs for mitigating climate change and correcting the unfairness of previous action. This reading states that those who have taken more than they were entitled to have failed to show appropriate moral restraint and must therefore counterbalance this in future actions. Issues of uncertainty are again relevant here and the issue of knowledge at the time will be discussed below, with some arguing that perhaps there should be limitation in the interpretation of "lacking moral restraint" to only a point after which it was known, or ought to have been known, that anthropogenic climate change was likely to occur. (Roser and Seidel: 120-124).

The "lack of moral restraint" requirement faces further challenges when examined, as it presupposes a standard of fairness where a distribution principle should explain the "fair share" in the first place. We need to know the meaning of "fair share" to apply this principle as it will tell us how the remaining shares should be allocated only if someone has already taken more than their fair share. (Roser and Seidel: 121).

Roser and Seidel suggest the second reading also faces challenges. This is through the requirement that individuals bear the costs of past countrymen, which would require some form of individual inheritance of duties. In order to make this more successful the focus would need to be on inherited benefits rather than inherited unfairness. Roser and Seidel conclude that this reading of the polluter pays principle is not convincing. (Roser and Seidel: 122-123).

In examining the discussion of Roser and Seidel above, the first reading appears to be more useful in distributing obligations in a fair 
and just way. It still cannot overcome many of the challenges of uncertainty and determining exact obligations would be difficult. This reading does impose a limited moral obligation on countries who have caused harm through their emissions, but how to distribute the obligations towards adaption and compensation are vague and not enough to assist in preventative action.

\section{ii. Beneficiary Pays Principle}

The beneficiary pays principle aims to incorporate the complexities of the real world in allocating responsibility to those who have benefited from the wrongdoing. In this section I will summarise the discussion by Roser and Seidel, which I believe accurately analyses the Beneficiary Pays principle. Roser and Seidel summarise the principle neatly saying, "If an offender wrongs someone and a third person benefits from the wrongdoing, then the third party seems to have a duty to the victim to make amends for the wrong - at least when the perpetrator is no longer in a position to do so." (Roser and Seidel:130).

Roser and Seidel apply this conception to climate change, stating that the prosperity in the "North" can be closely connected with a highemission economy, as without these emissions the North would not be as well off as they are today. These greenhouse gas emissions are leading to climate change that is causing the suffering of others. Applying the above conception of the beneficiary pays principle, we can see: 1) there is a wrongdoer (previous generations from the "North"), 2) a third person benefits from the wrongdoing (current populations in the North enjoying greater prosperity), and 3) a wronged party (those suffering from the consequences of climate change). (Roser and Seidel: 130-131).

The beneficiary pays principle is also a "historical" principle of distributive justice, as it "distributes the costs on the basis of the past." It differs from the polluter pays principle in its focus on the effects of harm or injustice rather than the causes. Justification for 
imposing costs can be made purely from the benefit derived from past emissions, regardless of the current actions of the individual. Roser and Seidel: 131).

Roser and Seidel identify three effects of past emissions that are morally problematic:

1. The effect of climate change as a harm.

2. The effect of the advantages as past unfairness.

3. The effect of inequality. (132).

The first effect focuses on the harm caused by historic emissions to people living in developing countries. The reading assigns adaptation and compensation costs to the beneficiaries of past emissions in proportion to their respective advantages. This correction of the wrong means that beneficiaries must bear the costs of ensuring that those harmed by past emissions have the best protection against climate change effects, or are compensated for the damage caused. This reflects the idea of "putting one's moral house in order" as the duty arises from the benefit obtained through the harm suffered by others. Roser and Seidel argue that this reading at best compliments the polluter pays principle, capturing forms of damage to the climate that are not covered by polluter pays. The reasoning is that, where it is possible to hold the polluter themselves liable, it would not make sense to hold the beneficiary liable. Another strong critique of the principle states that, it cannot always be the case that all undeserved benefits from a wrong obligate a beneficiary to pay compensation. It is only when there is an element of perpetuating, enabling, or exploiting the wrong where such an obligation arises. Past emissions do not perpetuate the wrong of climate change damage, which therefore undermines the validity of the first reading of the beneficiary pays principle as a principle for fair and just distribution. (Roser and Seidel: 132-136).

The second reading focuses on the unfairness that industrialised countries used more emissions than they were entitled to, and 
therefore must receive a smaller proportion of the distribution of remaining emissions. Countries would therefore receive a smaller share in relation to the proportion of benefits derived from past emissions. The compensation here is to counterbalance the lack of moral restraint that resulted in the benefits enjoyed. The critique of this reading is the same as for the second reading of the polluter pays principle - there is a presupposition of a different principle of distributive justice. This is because it requires that there is already knowledge of what a country was entitled to in the first instance. (Roser and Seidel: 133-134).

The third reading focuses on the inequality caused, or increased, between industrialised and developing countries due to past emissions. The remedy for this wrong would be to divide the benefits and disadvantages of past emissions equally. Therefore, advantaged industrialised countries would need to compensate developing countries to an amount that represents an equal benefit from the historic emission. "If a wrong is unavoidable, then everyone should benefit equally from it." This principle guides this reading of the wrong caused by past emissions. It imposes a duty on those who benefit unduly from the wrong. The issue with this reading is that it considers inequality in itself to be the reason for compensation. This looks more like the ability to pay principle (discussed below) where a wealthy country, by virtue of their relative wealth, must do more in compensating for the wrong of past emissions. This is therefore not clearly a beneficiary pays principle anymore. (Roser and Seidel: 133134).

Overall, these readings of the beneficiary pays principle are difficult to apply. Firstly, they require imagining what the world would have looked like without industrialisation through emissions intensive means. There would also need to be a system to differentiate between prosperity due to past emissions and prosperity due to personal skills and attributes. (Roser and Seidel: 137). 
iii. Historic Knowledge

Another aspect of historic emissions in relation to distribution of burdens relates to the knowledge at the time. It seems unfair to hold countries liable for emissions that were created when there was little to no knowledge of the harmful effects that would result (Pickering and Barry, 2012: 674). Similar to many other areas of law, retrospectivity is heavily discouraged as it undermines the stability and predictability of social relations. If someone in the future were to look back and criticise the use of cars by our generation, that would be acceptable. However, it would be a step further to therefore hold the future generations accountable for our actions in using our cars. This is essentially what is done through differentiated obligations and discussed in relation to intergenerational justice. Though it is understandable to want to attribute responsibility and ensure countries' obligations are a reflection of their contribution to the problem, the issue of knowledge at the time ought to limit this obligation to some extent.

This encapsulates the concerns around climate debt, primarily that transferring this obligation seems an unfair action to take. The argument against this would be that there is a need to tackle the challenge of climate change and it would not be fair to place the burden evenly across all countries. Why should a country that did not contribute to the problem (or had a lesser impact) contribute the same amount to the solution? Climate change presents its own peculiar circumstance in that several generations may have passed since the original action was taken. Furthermore, it is not the same as actions in war, where many of the people held accountable would have directly benefited from the situation or been involved through direct ancestors, such as parents or grandparents. In relation to climate change, the actions taken at the time were not done with any malice or intention to harm any other nation or its people. A balance needs to be found between the obligations from historic emissions and the recognition 
of a lack of blame due to limited knowledge and generational changes (Pickering and Barry, 2012: 676).

It is therefore difficult to attribute some obligation that is owed by descendants in countries that historically polluted more, to the current generation. Though the beneficiary pays principle attempts to address this concern by attributing the responsibility because one has benefited from the emissions of an ancestor, it is not clear to whom the obligation is owed. It does not seem that the obligation should be owed to developing countries because no wrong has been committed to them specifically (excluding purposive pollution in developing countries) in the emissions of developed countries in the past. Perhaps it could be owed to the world generally, the current and future generations that will have to adjust their expectations of life due to the actions taken in the past (Shue, 2014: 235). If this is the case, there would be less argument for the extra burden being placed on developed countries. The argument still holds however, when we consider the principles mentioned above, we can create a no-fault structure that can account for previous wrongs through outcome responsibility.

\section{Ability to Pay}

The Ability to Pay principle sets forth a different approach to climate change mitigation. The principle moves away from any focus on blame or previous emissions and instead focuses on who is able to pay for costs associated with climate change mitigation (Caney, 2010: 207). The principle looks to provide an "ahistorical" answer, through looking at aspects in the present for the distribution of obligations (Roser and Seidel, 2017: 140). Though this may appear unfair due to the notable difference in emissions between developing and developed countries, the principle recognises the immediacy of the climate change threat and looks to find the actors who will best be able to mitigate this. The distinction occurs because developed countries exploited resources in order to develop, which the 
developing countries are being asked not to exploit, constricting their right to develop. Furthermore, the developed countries became developed through this process and much of their industry was founded in practices that were resource exploitative (Shue, 2014: 183). However, as shown above, determining how to assign a fair amount of climate debt is a tricky process.

When considering the motivations for the distinction between developed and developing countries, I would argue that the ability to pay may be one of the fairest options available. Current prosperity may itself be considered a basis for distributing costs (Roser and Seidel, 2017: 140). If one has the ability to pay and rectify a moral problem then that might be enough justification for one doing so. The advantage of this solution is that the burden may be costly, but it is not too heavy for a country to bear as it is calculated in relation to economic capacity (140). This solution therefore also reflects the wording of the UNFCCC Article 3.1 which discusses duties in relation to respective capabilities (140).

The argument that many of the benefits for people in developed countries come from their exploitation of resources makes it understandable that they should carry some of the burden. I believe that an ability to pay approach would achieve this goal and therefore result in similar benefits as the Beneficiary Pays principle. If it is true that many of the developed countries are now in better positions, when determining who is able to pay it would primarily be the developed nations. The developing countries would then be liable for less of the burden but should still be involved as the issue is a global problem that requires collective action. The principle also neatly captures any countries that may have recently become heavy emitters and built powerful industry. This would not be achieved through an historic emissions or climate debt approach as the dates set are often too far in the past. For these reasons I argue the ability to pay approach achieves the goals of the Beneficiary Pays principle, without placing heavy burdens on those states that cannot afford it. 
The ability to pay approach may also be seen as fairer on those countries that may have done damage in the past but have not succeeded to turn this into economic industry. Some countries may have become very poor, therefore, trying to place obligations on them greater than on other wealthy countries seems unfair. Again, an outcome responsibility-focused approach may be best in this context. Countries that took part in causing the problem should also do their share in fixing it. However, perhaps a fairer distribution of the obligations would be an equal burdens approach (Moellendorf, 2009: 251). Much the same as the ability to pay approach, equal burdens is the idea that the burden be split in a way that each party involved is carrying the same burden relative to their ability to do so (251). The Ability to Pay principle is the wider notion that all states will be involved in the protection of the planet through using their resources, relative to their position, responsibly and for the collective wellbeing of all people.

There are also challenges to the ability to pay approach. Firstly, there is the argument that considerations made in relation to ability to pay are more pragmatic than morally compelling arguments (Roser and Seidel, 2017: 142). If we are looking for a just solution, then we need the moral justification to be present. However, this could be adapted so the ability to pay principle is framed differently. This framing could be for example, that those who have more than enough should contribute more, but never to the extent that they have less than enough (142). This could seek justice where everyone is sufficiently well placed, rather than some people having huge excesses. This is similar to the beneficiary pays model that discusses the notion of the wrong of inequality. This formulation of the ability to pay approach is one that treats inequality as a wrong in itself. The ability to pay principle expresses two morally guiding ideas; sufficiency and equality (145). However, there are further challenges that remain, such as defining and determining what "sufficiency" would mean for 
this formulation; should it be limited to subsistence emissions? And what is the measurable output? (142).

The ability to pay principle raises questions around what a country ought to do, as only the state itself could accurately determine what it is able to do. When moral philosophers say "ought" implies "can" it means that we can have a duty only if we are able to do that duty (146). A classic example is of the drowning child in a pond. If there is a child drowning in a shallow pond, you ought to rescue them if you are able. The inclusion of "if you are able" is to ensure there is not an obligation on those who would not be able to rescue the child, for example if the person were tetraplegic. However, Roser and Seidel present the argument that the converse of this principle may also be relevant, that "can" does not necessarily imply "ought" (146). They use the example of being able to play the piano, just because you can does not mean you ought to (146). Roser and Seidel argue that his extends to providing assistance, being in a position to help someone does not of itself mean you are morally required to do so (146). They use the following example:

"If you own a postage stamp and a Spaniard who is unknown to you has become depressed because he wants to own your postage stamp in particular, then you are in a particularly privileged position to help him - and, without a doubt, it would be generous and nice of you if you did so, but this cannot be required of you." (146).

They continue to say that if you were to give the Spaniard your stamp, it would be a supererogatory action. Roser and Seidel draw the parallel to climate policy and ask whether the distribution of costs of mitigating climate change on the basis of economic capacity would also be a supererogatory action, rather than a duty of justice. They acknowledge that this conclusion would be regrettable but not necessarily objectionable. (Roser and Seidel: 146).

I think there are problems with taking this approach to potential obligations where a significant harm is foreseeably produced. In the 
example of the Spaniard, it is not the case that: for every person you meet if you have a stamp they would like you must give that to them. When we look at climate policy we know that actions taken result in harm to others. One could take a proportionality approach to this and consider whether the harm that would be caused is significantly more than the inconvenience caused to those with the ability to pay. Whether this can be applied as a principle that creates obligations is debateable, however, it is important to consider the significant difference in the examples provided and the reality of the situation in climate change mitigation. It is not merely the fact that one is in a privileged position, but it is also the knowledge that the small inconvenience caused to one would result in widespread alleviation of harm. Furthermore, if we combine this with some of the other principles discussed above, perhaps this is not comparable to a person unknown to us, who wishes for something that is seemingly trivial. In the case of climate change policy and the potential use of an ability to pay principle, those with the ability to pay likely have some duties towards poorer states arising from previous actions. However, this would then bring into account historic conditions which the ability to pay principle aimed not to do.

Perhaps the framing of inequality as a wrong in itself may overcome the challenge of assigning obligations for an ability to pay approach, as this could remove the idea that the wealthy are doing more when they are merely correcting the wrong of significant inequality. Again, this would create subsequent issues of determining the acceptable level of inequality and how much a person should contribute. Finally, as highlighted above, the principle is ahistorical. This was one of the goals of the principle however, it is also a potential complaint as it therefore fails to take into account any historic responsibility (147). Therefore, similar to the beneficiary pays principle, the ability to pay principle may not be desirable as a stand-alone principle of distribution. 
However, throughout this thesis I will defend a qualified ability to pay principle as the best means of distributing obligations fairly, with respect to the right to develop and the norm of sustainability. The principle works best when supplemented by other principles, in order to address issues such as historic responsibility in some form. The ability to pay approach arguably already has this feature, as those with the ability to pay are often those who emitted the most and profited from this in the past. There are few outliers in this and therefore it is a principle that encapsulates much of the justice considerations we wish to address through a distribution principle.

These principles show that uncertainty remains, and this is an important element in the conflict at climate negotiations as nations are not willing to take on more than their "fair share" of the burden. A recurring theme in the principles discussed above is the accountability required from past emissions and for present additions to this. Though there is uncertainty, there is also a need to acknowledge and support developing countries as they have not contributed as much to the problems that are likely to affect them the most. The polluter pays and beneficiary pays principles both have historical insights. Though neither principle on its own creates a clear just and fair solution, it is important to recognise the justifications for these principles and incorporate them to some degree in the distribution of obligations. The ability to pay principle can be seen as a means of doing this (similar to the criticism of the third reading of the beneficiary pays principle) as it turns away from assigning blame and responsibility through historical accounts and instead is a means tested method of distribution. If the arguments for the historic approach have weight, this should be captured through an ability to pay principle as those countries that are better off are likely to be the ones who were previously heavy emitters. The ability to pay principle also removes any unfairness in relation to burdens that are excessive, as it is limited to what countries are able to pay. The other principles could also be limited in such a way but would then be less likely to reach the 
overall goal of climate change mitigation. Combining the principles in some form would be the most effective way to achieve the goal, doing so would be a significant challenge.

\section{Establishing a Right to Develop}

The formulation of the right to develop I will use is that of Moellendorf's which will be discussed in the next chapter. If a right to develop is understood as a right for countries to reach a basic-needs threshold of development, then an ability to pay approach should not limit this either. Countries that are not one of the historic emitters but have the means to pay for climate change mitigation would also be countries that are developed in the sense that they have strong economies and do not need a right to develop further. There are still issues with this approach, as discussed above, and the means by which countries have developed should be relevant in assigning responsibility. However, perhaps there can be an assignment of responsibility which is somewhat removed from the distribution of obligations. This would result in a distribution that is fair on countries by not creating a burden that is too heavy, that captures to an extent the historic emitters, and achieves the goals of distributing the climate change obligations, all without neglecting the recognition and acknowledgement of previous emitters and their contribution to the problem. By combining the obligation with responsibility now, and separately addressing historic responsibility there is a greater chance of success for the overall goal of climate change mitigation. The right to develop is intuitive. It would not be fair for some countries, who have historically been responsible for the current harm, to remain developed while other countries, who are often not responsible and are experiencing the negative effects of climate change, to be denied a right to sustainably develop.

The other side of this argument involves the norm of sustainability. This is the concern commonly presented by the argument that all actions must be sustainable, given current knowledge and 
responsibilities to future generations. The norm of sustainability is perhaps best reflected in the historic principles which assign responsibility for previously unsustainable practices. However, as we have seen, this is difficult to quantify and therefore difficult to use as a distribution measure by itself. This does not remove the importance of the norm of sustainability. Again, the ability to pay principle should be compatible with the norm of sustainability as it seeks to protect the environment through those who are best able to provide resources and have means to do so. The ability to pay principle does not, as a principle alone, promote the right to develop or any other practice that would exploit resources, it merely advocates for those who can pay being obligated to pay for environmental protection. The ability to pay principle appears to meet many of the demands of justice we seek in a solution to the distribution of obligations for climate change mitigation. The principle remains applicable for both a right to develop argument and the norm of sustainability argument. However, the ability to pay clearly leaves open the resources for those who are less wealthy to use in their development. It will target wealthier nations that do not need to develop, or have excess resources for development. There must be a balance achieved between allowing development and promoting sustainable practices. This is why I endorse the formulation by Moellendorf of a basic needs threshold. These restrictions will be discussed in the following chapters. 


\section{Chapter Two:}

\section{Climate Justice and Non-Ideal Theory}

This chapter will begin by outlining the conception of a right to develop, which I will use throughout this thesis. I will suggest limitations to this right through the norm of sustainability. This results in the formulation of a sustainable right to develop that Moellendorf advocates. The chapter then explores Laura Valentini's conception of non-ideal theory and applies this to the distribution of obligations in climate change agreements. Looking at the more realistic cases of partial and non-compliance, I will examine the implications of developed and developing non-compliance and then justify why this needs to be considered for climate agreements. This will be the foundation for my argument that the right to develop ought to be limited to a basic needs threshold.

One of the large disputes in relation to distribution of obligations is whether developing countries can balance their obligations for climate justice with their right to develop. I discuss Moellendorf's formulation of a right to sustainable development to clarify the demands of a right to develop in the context of climate change. Though he presents a convincing argument, the right to develop is problematic in a non-ideal context. However, the minimum requirement of a sustainable right to develop, to the level of ensuring basic needs are met, should be incorporated in any fair and just agreement.

In relation to issues of compliance, I will use Laura Valentini's two assumptions of ideal theory based on the conception by Rawls. These are: 1) All relevant agents comply with the demands of justice applying to them; and 2) natural and historical conditions are favourable (Valentini, 2012: 655). These assumptions are directly relevant to many significant areas of climate justice, especially for the 
developed and developing distinction. This chapter of my thesis will focus significantly on the first assumption, as this is the more contentious of the two in relation to climate change. The first assumption raises issues around the right to develop and the implications of partial or non-compliance.

Finally, I use the responses to partial and non-compliance outlined by David Miller to illustrate how the right to develop may need to be limited when considered in a non-ideal context. When states are only partially compliant, or even not compliant at all, there are serious implications for the allowance of a right to develop. This can also differ in significance depending on which countries' non or partial compliance we are considering. Large emerging economies and developed countries have different motivations behind emissions than least-developed and some other developing countries. When using Moellendorf's threshold of basic needs, the idea of a right to sustainable development is essential, but anything beyond this is difficult to defend, when balanced with the norm of sustainability.

\section{$\underline{\text { Right to Sustainable Development }}$}

The framing of the right to develop significantly influences the appropriate distribution principles. Moellendorf discusses a right to sustainable development which would be the most applicable in the context of climate change considerations. Moellendorf defines this right as follows:

"The right to sustainable development is a claim that least-developed and many developing states have the liberty to pursue energyintensive development and not be yoked with the same financial burdens that highly developed states must wear. This is a freedom not to have to assume an equal share of the demands of intergenerational justice, placed on the present generation on behalf of future generations on precautionary grounds.” (Moellendorf, 2014: 124)

This formulation does not include the important limitation that Moellendorf suggests, that of a basic needs threshold. The limitation 
is implied in the sense that he acknowledges the demands of intergenerational justice [future generations] and therefore there must be consideration of sustainable practices. However, he argues that developing states should not be not held equally responsible. This allows for some room for development, but still places limitations as developing states are not wholly exempt from responsibilities towards future generations. This formulation by Moellendorf reflects the differentiated duties discussed previously in this thesis, that there are duties shared globally but greater burdens ought to be placed on those who are more responsible (historic responsibility) or capable (ability to pay) in the face of climate change mitigation.

Moellendorf argues for two defences of this position. The first is the reasonableness of acting in good faith in deliberations. The second is, "derived from the value of fair terms of cooperation in pursuing the international goal of climate change mitigation." (124). Moellendorf is referring to formulations used in the UNFCCC, where Article 3(4) supports the idea of a right to sustainable development. Moellendorf is therefore indicating that commitment to the terms of agreement ought to be honoured, and this may already be enough of a justification for ensuring a right to sustainable development. In his first defence, which he states is relatively noncontroversial, he is arguing that good faith requirements of agreements ought to be honoured, similar to a requirement to keep promises and be held to your word. This is a basic decency required for the world to function, especially in relation to problems of a global nature that requires collective action. The second defence addresses the substance of the agreement and highlights issues surrounding unfair bargaining positions of states and means to ensure that terms are fair to all parties to an agreement. The balance of power heavily favours wealthy countries in international negotiations. Often the least-developed or developing countries will not have the resources to send large teams of negotiators to represent them in the many different concurrent negotiations. It is therefore important that ideals of differentiated 
responsibilities are respected. These are required to create the conditions necessary for equality in the negotiations and in the actions that will be required of states in mitigation policy. The position Moellendorf argues for is an attempt to balance the obligations to future generations that that is demanded by sustainability, with the obligations to current generations to allow for development, especially for the right to develop to stage where all basic needs of society are met.

Moellendorf specifically discusses how this right to develop is limited by sustainability, however, he also notes that the UNFCCC would allow for development beyond the basic needs threshold. Moellendorf argues for a limitation on the right to develop that may be achieved through monitoring and thorough examination of a state's development policy to ensure it is consistent with the norm of sustainability. The sustainability to which he refers is of the whole world, not the individual state. Moellendorf continues, stating that the right to develop is a right in the context of a sustainable global energy policy. He argues that in order to develop rapidly, states need access to cheap energy and currently that would mean access to fossil fuels. This factor is shifting, as renewable energy becomes more affordable, however, it is still not cheaper than fossil fuels in the short term. (Moellendorf: 131-132).

Moellendorf argues for two ways in which international agreements can accommodate the needs of the least-developed and developing states, they are: "(1) Either these countries could be allowed to use fossil fuels without the same restrictions placed on highly developed countries or (2) the purchase of renewable energy and renewable energy-generating technology could be subsidized by highly developed countries." Therefore, Moellendorf argues that the right to sustainable development will limit policy options available for climate change mitigation. Moellendorf continues, stating that a proposal to mitigate climate change through a principle that would restrict the right to develop for some countries, and maintain the high 
level of development for others, would be objectionable because it would not achieve the distribution of mitigation obligations in a fair manner. (Moellendorf: 132-135).

The norm of sustainability may limit the right for poorer states to use fossil fuel energy to develop. There is an overall goal to limit temperature increase to two degrees, and any addition to greenhouse gases seriously impedes this goal. If we still want to allow a right to develop, as Moellendorf argues we must, then I suggest that the burden should fall on the rich states to provide opportunities for clean development. It is not the case that there are no clean means of development, but there are financial barriers. It is in everyone's best interests that if developing states are to develop, they do so through the cleanest means possible. These resources ought to be provided by developed states who have the wealth and resources to allow for clean development. The problematic part of Moellendorf's argument is that he advocates for a right to develop that is more important than the norm of sustainability. Furthermore, he does not necessarily limit this right to development through clean technology only. It is understandable that both are necessary, but beyond the more minimal formulations of a right to develop, it is hard to justify prioritising of this right above sustainability.

Moellendorf himself identifies this concern. He determines that it arises because the right to sustainable development must be a group right, as pursuing development can only be a collective act. Moellendorf identifies two concerns regarding group rights, firstly, that it is an inflation of rights, and secondly, the character of group rights in itself. Moellendorf defends against the first challenge by stating that the right to sustainable develop need not be a human right, however, if a state acts in a way that prolongs poverty it can be argued that human rights have been violated through those actions. Therefore, it need not be considered a new human right, but rather a right that, held collectively, can encourage and support claims of violation of other basic human rights. If states do not adhere to the 
principle of the right to sustainable development, they will likely violate basic human rights which arise in the context of poverty. The right to sustainable development can be considered as a principle, and a group right, and not as an additional human right to avoid the challenge of rights inflation. (Moellendorf: 144).

For the second challenge, Moellendorf suggests that a group right to sustainable development will promote individual human rights rather than undermine them (145). A concern surrounding group rights is that they might undermine individual rights. Moellendorf argues this is not the case with the group right to sustainable development, as the overall aim will likely increase the fulfilment of individual rights with improvements to society through better sanitation, access to education, health services and means of income (144). I believe this also connects with the earlier discussion in relation to the respective bargaining positions of wealthy and poor states. A group right may be easier to advocate for in international negotiations and if secured, this group right can act as a foundation for any related individual human right. A right to sustainable development encompasses rights to the basic necessities for life which many in extreme poverty are currently lacking. There may also be greater accountability through the international process. Individuals who suffer from extreme poverty are unlikely to be able to make claims for the violation of their human rights individually, but through a collective right to sustainable development they could argue violations of this group right resulted in violation of their individual rights. I support the view of Moellendorf, that individual rights will not be threatened by the introduction of a group right to develop, and that the group right to develop in particular will likely enhance related individual rights.

There are other challenges to the right to sustainable development, such as that outlined by Posner and Weisbach. They propose the principle of International Paretianism, which states: "all states must believe themselves better off by their lights as a result of the climate treaty." (Posner and Weisbach, 2010: 6). Posner and Weisbach argue 
that if the right to sustainable development is not a fundamental human right, then perhaps it should not be given more importance than other important values, like sustainable use of resources (Moellendorf, 146). The argument from Posner and Weisbach, with the principle of International Paretianism seems reasonable but is difficult to apply in the context of climate change. It has already proven difficult, for many reasons, to determine a principle that will allow for all states to believe themselves to be better off. Moellendorf explains the positive framing of International Paretianism as favourable on feasibility grounds, as it selects what is viewed as being best for all countries (149). A right to development would not be selected as it creates greater obligations on developed states, and therefore is a solution that is not perceived to be in the best interest of highly developed states (149).

Moellendorf challenges this formulation, as the solutions suggested by International Paretianism do not appear to hold when considered from the perspective of developing countries. Developing countries will also not perceive a solution as in their best interests if it does not afford them some right to sustainable development (149). International Paretianism is not a plausible principle, as even a minimal right to develop would be unlikely to pass it. It needs only one state to determine that the conditions are not in its best interests for the challenge to fail. If we extend the conditions to the international stage, there would be no way to form agreements that all states, developed and developing, would consider to be in their best interests and therefore the principle is likely to be of little use in serious international negotiations.

Moellendorf presents a strong argument for the defence of a right to sustainable development. However, it is important to note that limitations must be placed on this right. Moellendorf advocates for a minimum requirement that development involves being able to guarantee basic rights to all people. This is a lower threshold than often suggested by international agreements. This puts a basic rights 
threshold requirement into tension because, as Moellendorf establishes, some of the justification for obligations is formed from contracts parties agree to through treaties and conventions. The right to sustainable development is already a refined principle from the original right to develop, as it limits this right in line with the importance of sustainable practices. However, Moellendorf appears to be arguing for a right to develop that would exceed the sustainability requirement. This may be due to the considerations of intergenerational and intragenerational justice which I will discuss in the following two chapters of this thesis. These justice considerations include for instance, the importance of considering the welfare of current generations in intergenerational justice, rather than focusing solely on whether we ought to maximise benefits for future generations. However, this section will continue to examine how nonideal contexts may influence the appropriateness of a right to develop principle.

\section{Assumption of compliance with the demands of justice}

The assumption that states will comply with the demands of justice applying to them, faces many of the same challenges as the distribution principles discussed in the previous chapter. Significantly, the demands of justice that apply are not specified, which therefore leaves the question of which distribution principles to use unanswered. Therefore, it is difficult to know how to satisfy this assumption, and the assumption is left open to wide interpretations as to what demands of justice apply to which states. I have argued that the ability to pay approach is the most just distribution principle, however, in a non-ideal context this may face greater challenges than other principles discussed in Chapter One.

The previous discussion of "ought implies can", is also relevant in this assumption. The assumption that states will comply with the demands of justice implies that the demands of justice will consider what the state can do. The considerations of what states can do may 
limit the possible action that can be justifiably assigned. However, we need not go as far as suggesting that poorer countries cannot do anything to mitigate climate change, they will still be able to contribute relative to their position. It is important to note that these sorts of secondary assumptions, present behind those identified by Valentini, have a significant impact on the applicability of these assumptions.

The previous chapter identified that, through several different methods of distribution, there is a reoccurring theme of a greater obligation being owed by developed states. This assumes full, or significant, compliance. Though there is not a clear principle for the distribution of obligations, and therefore, no clear guide of the demands of justice, there is a reasonably secure idea that developed states must do more in mitigating, adapting, and addressing the challenges of climate change. Through the uncertainty one can therefore argue that, without specifics, we can proceed on the assumption that the demands of justice will be greater on developed countries than developing countries. This leads into the discussion of what can be done when we remove the assumption that the demands of justice will be complied with.

If we remove the assumption that states will do what justice demands of them, the problem of climate change becomes more threatening. More action needs to be taken to reach the overall goal of mitigating devastating climate change. The urgency of climate change mitigation is already challenged by the lack of certainty in assigning responsibility and obligations. This is compounded by states not doing their share as justice demands. Although we have not established what a country's fair share might be, we have established that developed states must do more than developing states. This is an ideal-theoretic conclusion and an important guide on how to justly distribute obligations. It appears as though there is a need for ideal theoretic factors, even in non-ideal contexts. 
I believe we can therefore argue that there is a greater injustice if developed states fail to meet their targets. The current distribution of obligations reflects some of the ethical considerations needed such as historic responsibility and ability to pay. If it were the case that either only a developed state or only a developing state was not meeting their obligations, then there would be a rejection of this assumption of compliance and there would be an injustice caused by the state not doing their share. However, in the current situation, both categories of state are not meeting their obligations. There would therefore need to be consideration of how far short states are in their failure to comply. However, this analysis would be in accordance with constructed obligations, such as treaty or legal agreements, rather than the demands of justice. The demands of justice point to greater obligations for some over others, namely developed states who contributed more to the problem. Therefore, it is more likely that we will find a failure by developed states to meet the presumption of compliance. Even in relation to the contrasted obligations, it is more likely that the developed states will fail to meet their obligations by a greater extent, due to the differentiated obligations.

However, when the ideal-theoretic assumption that states will comply with the demands of justice is removed, it becomes harder to justify a right to develop. The right to develop requires a careful balancing of obligations and allowances for emissions. This cannot be done when there are large uncertainties around the actual compliance of states to targets that are assigned to them. In a non-ideal context then, the right to develop ought to be limited to ensure a balance with the norm of sustainability. The response is to consider what else can be done in the face of partial or non-compliance to the demands of justice.

\section{Partial and Non-Compliance}

There are three standard responses individual states can make to noncompliance or partial compliance in international agreements (Miller, 2011: 233): 
1) Withdraw compliance: if some states are not compliant then there is no justification for the sacrifice of other states

2) Continue with the same goals: essentially ignore the withdrawal of states and continue with the agreed upon goals

3) Increase goals: an adaptive strategy to achieve the overall goal by spreading compliance across the remaining states.

The issue of non-compliance by developed countries may have different implications than that of developing countries. This is primarily because of the ideas mentioned earlier in this paper about climate debt and historic emissions. There are other relevant considerations such as a developed country's ability to pay and the potential impact of their non-compliance. Currently there are differentiated responsibilities which acknowledge the right to sustainable development mentioned above. However, even with these measures many countries are failing to fully comply with the targets set. There may be more significance in some countries' lack of compliance over others. For instance, if some developing countries are not meeting their targets, but are emitting more in an effort to establish more efficient practices in the future, this may be more permissible than a developed country that is failing to meet its targets purely because it wants to increase profits. The reasons for emissions therefore, may have an impact on the acceptability of emissions, especially those above the levels agreed upon. Furthermore, taking the arguments of Moellendorf, it may be permissible to allow developing states to develop, whether that be with a goal of future efficient practices or not. Two of the largest emitters are known as "emerging economies", China and India, and their lack of compliance can be viewed more negatively than the least-developed and some other developing countries who may be exceeding emissions targets purely based on sufficiency emissions. These emerging economies are experiencing huge growth which has seen these nations' emissions becoming the largest in the world. These go beyond merely sufficiency emissions and therefore need to be incorporated into 
considerations of obligation distributions. New solutions will be needed for situations like that of the least-developed nations and the emerging economies, and these are discussed in Chapter Five.

The potential impact of non-compliance by any country will likely be significant. International agreements often are weakened to be more inclusive, however, this means that anything less than the stated targets will not be enough. In achieving such agreements, it is unlikely that countries will step up to do more than they had agreed to. Therefore, there is an assumption that, at best, countries will continue with the agreed targets but not go beyond (Shue, 2011: 243). The impact of these actions will affect developing countries first and more significantly. Firstly, developing countries will likely be the first to experience the worst effects of climate change, such as severe weather events (Moellendorf, 2009: 248). These are becoming more frequent and although manageable, are devastating in poorer areas without the infrastructure to survive the weather itself or its aftermath. This could potentially obligate all countries to reach their climate goals in order to avoid accountability for the damage of climate change.

This relates to the central distinction between developed and developing countries: their ability to pay. As stated above, it is more likely that developed countries will be better able to pay for the costs of climate change mitigation. This perhaps assigns them an obligation to do so, since they may be the only ones with this ability. However, an ability to pay mechanism should not be divided along the developed-developing distinction. Any country with the ability to pay ought to be compelled to contribute to the mitigation of climate change, following the "ought implies can" approach. The minimal moral threshold therefore, is that only states that cannot contribute to mitigation are exempt. There are very few states that would fall into this category, perhaps only some of the least-developed states. 
The problem of partial compliance may alter our perception of available options. In relation to climate agreements, there do not appear to be repercussions for lack of compliance that create enough incentive to motivate full compliance. Partial or non-compliance can often be easier for states who do not wish to do their share and hope that other states will compensate. The urgency of climate change means there is no time to wait for all countries to fall into line, it may be the responsibility of those who can contribute to do so until there is a viable solution, even if that means doing more than their original share. The issues highlighted above ought to compel action, but how to achieve this motivation is yet to be determined.

If we can promote the acceptance of greater responsibilities by states, the assumption of compliance to the demands of justice would not need to be a central element for consideration in the distribution of obligations. However, it is not likely that this result will occur. Therefore, when we remove the assumption that all states will comply with the demands of justice placed on them, it becomes more likely that we will have to limit the right to develop. There would be no safe way to calculate a distribution that leaves room for an emissions allowance in addition to the minimum sufficiency emissions. The potentially devastating effects of climate change would seem to be a more urgent priority over the right to develop, even for developing states and especially for their future generations. When considering the discussion of what a right to sustainable development would be, the urgency and pressure of climate change impacts may require climate change mitigation to be prioritised. Partial or non-compliance with the demands of justice would also limit motivation to act, making it even harder for the remaining states to go beyond their current goals, or even maintain them.

The implications of partial or non-compliance are particularly pressing in current climate negotiations. Firstly, there has been the recent withdrawal of the United States from the Paris Climate Agreement. This means that their compliance to the agreed upon 
goals cannot be included. This is compounded by the fact that even if all countries complied with their promised action, it would not be enough to limit the global temperature increase to below two degrees, and nowhere near the more desirable limit of 1.5 degrees. These factors are an important reminder of how the practicalities of international agreements are already falling short of appropriate action. The use of non-ideal theory and the assumptions outlined by Valentini illustrate the reality of the situation and how to evaluate the distribution of obligations without the limitation of assumed compliance, which distorts the actual contributions made by states.

More action is required, but it is still unclear how this is to be achieved. The questions around the right to develop become more difficult in this environment. A right to develop might further restrict ambition and potential action by many states when greater action is needed by all states. As discussed above, a principle such as International Paretianism reflects what many states would desire, however, this principle is unlikely to be met by both developed and developing countries. The right to develop ought to be limited to the basic needs threshold, as this is the minimum required for a just distribution. Anything beyond this basic needs threshold appears to be currently impractical. When we consider partial or non-compliance by removing the assumption of states complying to the demands of justice we can get a clearer view of the reality of the situation. Though states ought to comply with the demands of justice, it has already proven difficult to assign these demands with any certainty. If this cannot be achieved, then the right to develop needs to be restricted to create stronger commitments to climate change mitigation.

Removing the first assumption highlighted by Valentini shows that action on climate change needs significant revision. Agreements are still created with the assumption of full compliance which is inaccurate and insufficient to reach the goal of climate change mitigation. Furthermore, we now have a direct case of a state 
rejecting its obligations, with the US, one of the largest historic and current emitters, withdrawing from the current climate agreement. States may agree that the demands of justice on them are less for particular circumstantial reasons, however, I have previously established that there ought to be greater obligations for developed nations to account for historic emissions. With these considerations in mind, it appears as though the right to develop can only be considered as a limited right if the ultimate goal of climate change mitigation is to be achieved. To achieve a just distribution of obligations, a basic needs form of sustainable development is the minimum requirement for any agreement. However, anything beyond this is difficult to justify in the current environmental context.

\section{$\underline{\text { Assumption of favourable conditions }}$}

The second Rawlsian assumption discussed by Valentini states that natural and historical conditions are favourable. This refers to whether a society is sufficiently developed to realise justice (2012: 655). The natural and historical conditions determine the ability of states to adhere to the requirements to make justice possible. There is a connection between the assumptions in relation to compliance with the demands of justice. As stated before, the demands of justice must account for the ability of a state to comply. Similarly, this assumption states that the relevant conditions are favourable. However, in this formulation we must consider the world as a whole, rather than individual states.

Society appears to be sufficiently developed to realise justice. If we assume that historic conditions are favourable, the ability to pay principle would be the fairest option. The other element of this assumption is that natural conditions are favourable. This must be considered when solutions are proposed, as it may be relevant to evaluate who is in the best position to realise these solutions. For instance, in relation to forest preservation (both as a resource and as a carbon sink) there is more that can be done by developing states than 
the developed in most instances. Therefore, these actions must be undertaken by states in the position to do so. This would limit development, as those wanting to use the resource for development would need to find an alternative method. If we remove the assumption that natural and historical conditions are sufficiently developed, the ability to pay principle can be understood as an unfair principle of distribution due to the lack of acknowledgement of historic conditions. However, even if conditions were not sufficient, the ability to pay principle would be the most complete solution and would provide the fairest solution for the distribution of obligations. The lack of acknowledgement of historic conditions is less relevant when we approach this assumption from the position of society as a whole. Overall, society is likely in a position to realise justice, so this assumption does not have the same contentious weight as the first assumption.

Further questions remain around this assumption. Firstly, one must determine what "sufficiently" developed means. The sufficiency threshold is difficult to determine as it is vague and there are many measures of development that may need to be considered. For instance, it cannot be purely an economic measure as some states might focus on different measures, such as Bhutan's Happiness Index. One option would be to ignore these outliers and create an economic sufficiency measure in order to distribute obligations. There could be objective measures of economic development that could then determine contributions despite different priorities. This would be dismissive of some countries' values, however, to work towards a global goal, a common conception of sufficiency must be agreed upon. A sufficiency that focuses on economic factors would also align with the ability to pay distribution principle.

In the previous part of this chapter, I established that there is a right to develop in some form, however how this ought to be realised will require a balancing process with the norm of sustainability. If we determine that society is sufficiently developed to realise justice, then 
there must be a means to distribute obligations in a just and fair way. It is unlikely that this assumption is not satisfied in the current case, the resources and knowledge are available, and it is merely that the fairest solution still needs to be found.

\section{$\underline{\text { Conclusion }}$}

The two assumptions identified by Valentini show that there are elements of the discussion around climate change obligations that are not fully explored. When we remove these assumptions, we can see that behind them are important considerations for justice in the distribution of obligations. Without these assumptions it is clear there is still a lot of work to be done to reach the overall goal of climate change mitigation. Current efforts are not even close to achieving this with assumed full compliance let alone with more realistic, partial compliance.

One of the large disputes in relation to the distribution of obligations is whether developing countries can balance their obligations for climate justice with their right to develop. This will be the focus of the next chapter. Primarily, this balance is one that is different for each state and adds further complexities to the decision making around the distribution of obligations.

Considering the global nature of climate change and the need for collective action there are serious consequences for non-compliance, but even partial compliance is unlikely to be enough. Climate agreements are centred around creating goals and obligations in an ideal situation where all countries participating will fully comply with the targets presented. When examining the second assumption of favourable circumstances, it is likely that the assumption holds, and society is sufficiently developed to realise justice. Therefore, work must be done to determine the most fair and just solution to distributing climate change mitigation obligations that can both respect the right to sustainable development and the urgency of climate change. Partial-compliance presents a serious challenge to a 
truly fair distribution of obligations, but it must be accounted for in formulating the distribution. 


\section{Chapter Three:}

\section{Intergenerational Equity}

This chapter focuses on some intergenerational justice considerations relevant to the distribution of obligations for climate change mitigation. I will discuss Moellendorf's Cost Principles and Caney's Social Discount Rate scenarios. These frameworks both explore our relationship and obligations to future generations. The consideration of future generations is essential in climate change discussions, as they are an integral reason for protecting and preserving the environment. While in earlier chapters, blame and responsibility may have been placed on past generations, the same could be done to our generation if we do not do the right thing in the eyes of future generations. Our obligations to future generations must mirror or exceed what we would have wanted past generations to have considered for our well-being. This chapter therefore supports the limitation of the right to develop to the basic needs threshold, as much beyond this would likely be detrimental to future generations and would therefore be unjust.

Using Moellendorf's formulations, I argue that the principle of Intergenerational Equity will be best suited to accommodate intergenerational justice that truly considers justice across generations, instead of the common approach of prioritising needs of future generations at the expense of the current generation. It is evident that it is in the best interests of all generations to ensure that extreme poverty is addressed, and all people have their basic needs met. However, it is also important that the norm of sustainability is recognised to protect and preserve a fair share of resources for future generations. As argued in Chapter One, there is some justification in assigning responsibility to those who exploited resources and used more than their fair share in the past, and there is no reason to think this would not extend to generations in the future. The principle of 
Intergenerational Equity brings together the considerations that must be made to balance the right to develop with sustainable practice to best serve all generations.

I then examine Caney's social discount rate scenarios to determine whether it is possible to assign some of the financial burden to future generations, considering their likely greater wealth and larger population size. This argument is one that recognises the urgency of climate change action, but also that urgent action is needed to ensure basic rights are being met. If these basic rights can be met, it is even more likely that there will be greater wealth in the future and that extreme poverty will be much less prevalent or even eradicated. However, Caney identifies the importance of sustainability in practices today, and urges a limitation on the amount of discounting that can be allowed. Given that future generations have no say in the principles that govern our behaviour, we should err on the side of caution. Furthermore, we will not be able to compensate for unrestricted use of resources through financial means and may undermine the ability for future generations to generate wealth, if the climate that we all depend on is irreversibly damaged.

\section{Cost Principles}

Moellendorf discusses three principles for assigning the costs of climate change and then applies to different scenarios of developmental justice. This section will discuss the principles of assigning the costs, while the following part will discuss the developmental justice scenarios.

I quote Moellendorf's principles below and I will discuss each principle in turn (Moellendorf, 2009(b): 207):

“(1) Future Optimality: Present energy policy should produce an optimal sum of the foreseeable future costs and benefits of $\mathrm{CO} 2$ emissions. 
(2) Future Sufficiency: Present energy policy should produce a sum of foreseeable future costs and benefits of $\mathrm{CO} 2$ emissions that at least ensures the maintenance of just political and legal institutions.

(3) Intergenerational Equality: Present energy policy should produce foreseeable future (adaptation) costs of $\mathrm{CO} 2$ emissions whose proportion to overall future economic output is equal to the proportion of (mitigation) costs to output of the present generation."

i. Future Optimality

Moellendorf explains that future optimality can be considered in two forms; aggregate or per capita. The per capita approach is less common in the literature and takes account of population growth. This is a significant factor when considering the weight of obligations placed on future generations, as there will be many more individuals in the future, so the burden would be less per capita (assuming the same burden). The more common approach is the aggregate approach which compares the burden across populations of the same size. Moellendorf quotes Derek Parfit's Same Number Quality Claim that states: "If in either of two outcomes the same number of people would ever live, it would be bad if those who live are worse-off, or have a lower quality of life, than those who would have lived." (Moellendorf: 207).

This view has been criticised as unrealistic because it is unlikely the population size will remain the same. Moellendorf draws on the critique by James Woodward which states that this creates a demandingness issue for the present generation. Moellendorf states that this criticism is applicable to both forms of the Future Optimality approach because both forms require present sacrifices to maximally benefit future persons. Moellendorf continues, stating that this approach conflicts with our intuitive understanding of the impartiality between generations, as the approach heavily favours the well-being of future generations while discounting or dismissing the interests of 
the present generation. One's moral standing ought not depend on the generation into which one was born. (Moellendorf: 207-208).

In my view, this principle advocates for intergenerational justice, but appears to weight the future generation's needs more heavily than those of the present. There is no mention in this principle of considerations for maintaining or improving conditions for the current generation. To provide an "optimal" future, sacrifices would need to be made now. However, if the principle aims to optimise the future, it must allow for the development of those living today to at least a basic needs threshold. In restricting development, the future would likely not be "optimal" as the consequences of extreme poverty on future generations would also increase in significance. There is room in the definition of this principle to allow for considerations such as the costs of poverty on future generations, however, this is more relevant to the next two principles. On the current understanding of future optimality, I do not think this truly supports intergenerational equity as it fails to give adequate weight to the needs of the currently impoverished and their right to develop, focusing instead on the needs of future generations as a priority.

ii. Future Sufficiency and Intergenerational Equity

The Intergenerational Equity approach acknowledges that future persons might have more absolute costs than present persons. However, this is deemed permissible if economic growth is maintained and therefore there is greater wealth in the future. This approach considers proportional equality rather than absolute equality which therefore allows for the consideration of the economic growth that may result from emitting activities. (Moellendorf: 207).

Moellendorf argues that Intergenerational Equity guarantees Future Sufficiency, as under Intergenerational Equity future people would do just as well as they would under Future Sufficiency. Future Sufficiency therefore, may require less of the current generation than Intergenerational Justice. Moellendorf differentiates forward looking 
and backwards looking considerations for evaluating between these two approaches. The forward-looking consideration is a choice between "assuming more mitigation costs now to equalize costs between generations or allowing the possible assumption of fewer costs now so as only to ensure that just institutions are possible in the future." Looking backwards, the consideration is a choice between, "assuming fewer adaptation costs now because earlier generations chose to equalize or assuming greater adaptation costs now because previous generations only mitigated enough to preserve just institutions." (Moellendorf: 212).

Moellendorf outlines an argument for why one would select Intergenerational Equity over Future Sufficiency as follows: " 1 . The parties would prefer previous generations to have maximally mitigated their climate change adaptation costs.

2. The parties would prefer to minimize the costs of mitigating future climate change.

3. All other things being equal, Intergenerational Equality best satisfies the preference stated in the first premise.

4. Future Sufficiency best satisfies the preference stated in the second premise.

5. The parties are constrained to choose only the principle that they would prefer earlier generations to have followed.

6. The parties are constrained to select Intergenerational Equality." (212).

Moellendorf calls this the "Equality Argument". Premises two and four are to illustrate the merits of Future Sufficiency but do not add, logically, to the argument overall. The key premise for deciding between the two approaches is premise five, as it provides the rational reason for picking Intergenerational Equity over Future Sufficiency; otherwise the argument would reach an impasse. Premise five therefore reflects our intuitive desire for generational impartiality as 
well as providing a definitive answer for the principle to select. However, Moellendorf also states that premise five would seem to suggest a Future Optimality approach would be favoured, as all generations would prefer earlier generations to have followed the path that lead to their maximal benefit. This can be ruled out in deliberation, if we consider that there will be future generations and the parties cannot assume there will not be. Therefore, there will be reason to consider the welfare of future people and how to limit the costs of adaption and mitigation for future generations (Moellendorf: 212-214).

The argument for Intergenerational Equity provides a means of ensuring all generations are considered in deliberations. Although Future Sufficiency considers the needs to the current generation as well, it is arguably weak in its overall advocation for future generations. Though there is a difficult balance to meet, the needs of future generations should be considered, as premise five states, according to what the parties would have preferred earlier generations to have followed. This would allow for considerations of the development needs across generations. As stated above, issues relating to lack of development will continue and often worsen in the future if not properly addressed. For any generations then, the preference ought to be principles that balance development and the norm of sustainability. It is in the best interest of current and future generations to ensure that the basic needs of all generations are met, as this will create flow on effects into future generations. It will also likely reduce costs of addressing poverty later, when there may be many more impoverished people if nothing is done now. However, it is also important that practices are sustainable to ensure there are enough resources available for future generations and that conditions on Earth continue to support life.

The balance ought to include at the least, a right to develop to a basic needs threshold, to reduce severe poverty. The norm of sustainability must be promoted but be restrained by the demands of this limited 
right to develop. It is not only in the best interests of this generation, but also future generations if there is proper consideration of the costs and also the injustice that will occur if either of these principles is extended too far without consideration of the other. Therefore, the principle of Intergenerational Equity is the best equipped to deal with deliberations of what policy options ought to be adopted to promote both of these important factors, the right to development and sustainability, across and between generations.

\section{Determining the Social Discount Rate}

Simon Caney discusses the next element of this chapter in his paper, Climate Change, intergenerational equity and the social discount rate (2014). The social discount rate relates to the amount we are willing to sacrifice now, to avoid costs in the future. He discusses three positions:

"A. Pure time discounting gives us no reason to delay taking action to mitigate climate change (or for adopting a more gradual approach when implementing mitigation policies).

B. Growth discounting and opportunity cost discounting can only justify very limited justification for delaying action to mitigate climate change.

However,

C. Growth discounting might (subject to two conditions) give us reason to pass on some of the costs of mitigating climate change (and adapting to climate change) to future generations." (321).

Caney raises the consideration of whether current generations may (or should) treat future generations as moral equals, or whether they may (or should) exercise time preference (323). The latter option would go beyond the considerations raised by Moellendorf and suggests dismissing future generations altogether. However, Caney finds that all three positions described above still require minimal delay in actions to mitigate climate change. Similar to the discussion above, 
Caney states there is no reason to disadvantage someone purely because they were born later (324). Therefore, some consideration of future generations must still be made. Pure time discounting would be beneficial to future generations as it is a principle that advocates for urgent action in mitigating climate change. However, I believe this perhaps fails to account for the competing priorities of states, especially developing states in addressing the needs of the global poor today. Caney also notes that some argue that future generations will likely be wealthier than us, so we may prioritise the current generation as it would be wrong to have the poor make sacrifices, so the rich can be richer (327). This would be the opposite of Moellendorf's Future Optimality approach, arguing in favour of the current generation over future ones. This would benefit the global poor, by providing some allowance for a delay in mitigating climate change. The revised suggestion of option $\mathrm{C}$, above, would also allow for financial assistance that may increase the access, and therefore speed, of development for the least-developed and developing nations. The argument also supports the Intergenerational Equity argument that Moellendorf endorses, as it is about recognising the wealth of the future in order to discount the costs necessary for the present generation.

Caney calls this "Growth discounting" which he describes as: "People in the future will have more economic wealth and it is wrong to make the poor (current generations) pay rather than the rich (future generations)." (328). However, Caney identifies questions that are raised by this theory. The most challenging question is whether future generations would be wealthier. Furthermore, will they be wealthier even given harmful effects of climate change? (328). These questions raise the same issue that plagues all climate discussions, the issue of uncertainty. Can we defer costs to a future generation on the assumption that they will be wealthier? Would we be doing a significant harm if it turns out that the deferred costs are not passed on to a wealthier future generation? It seems unfair to pass on a debt 
when we cannot be certain that future generation would be in a better position. This is especially relevant when we consider the follow up question of what impact the onset of climate change might have on the wealth and welfare of future generations. The damage and costs related to climate change will likely be significant, and regardless of the actions we take now, adaptation and mitigation efforts will still be required for future generations.

This is why Caney's option C constrains the permissible actions to deferring only some of the costs of climate change adaption and mitigation to future generations. Even if we determine that it is highly likely that future generations will be wealthier than current generations, only a limited amount of the costs can be deferred to them. When we consider the other costs that will also be highly likely to occur in the future, it would not be fair to defer the costs. If our justification for deferring costs is to be fairer to the poor of the current generation, then we cannot place heavy burdens on future generations who will also have costs to bear from the actions of the current generation and previous generations. Furthermore, one can question who would bear the costs in future generations. Similar to the situation today, though the costs are not directly borne by the poor, it is the poorest in society who suffer the most from the costs of mitigating and adapting to climate change. As Caney states, "there are limits to the extent to which the destruction of natural resources can be addressed by the substitution of capital and human resources" (330). We cannot prioritise economic growth and exploit resources forever, but how and when this is permissible remains unanswered. Caney states, "in the context of climate change, the argument would be that it is better to delay mitigation and invest in technological innovation because the resources that would be spent on mitigating now will generate much greater mitigation benefits if we invest instead." (331). Though later in this thesis I support the investment in technology as an important step forward in addressing the challenge of climate change, there must be limits to this approach. The costs of 
delaying action may make the dependence on future innovation redundant. Here Caney discusses the principle of deferring costs, which he outlines as follows:

"(i) the appropriate action is - contrary to the first growth discounting argument - to act now and to mitigate climate change.

(ii) the costs of this mitigation need not necessarily be borne by contemporary generations but can be passed on to future generations." (333).

This appears to be an intuitively reasonable principle, which accounts for both the costs and the urgency of climate change mitigation. This best reflects the situation that international diplomacy currently requires. The unknown variables about the future, such as what innovation may arise, the wealth of future generations and the welfare of future generations, all place doubt on the ability to defer costs to future generations. However, when mitigation is required, if it cannot be financed currently, there may be justification in deferring some costs in the hope that there will be future societies for future people to benefit from. We are already seeing the impacts of climate change induced stressors around the world, such as famine, and the resulting conflict over land, food, and water resources, as well as the increase in extreme weather events that cause extensive damage to infrastructure and communities. The welfare of the current generation is completely dependent on climate change mitigation, and therefore there are strong grounds to allow for some deferment of the costs of such mitigation. However, this must be limited to an extent, as we cannot over burden future generations for the actions of our generation, for a problem they did not create, and for costs that they did not agree to.

The final approach Caney explores is sufficientarianism, again echoing Moellendorf's Future Sufficiency. However, he suggests this position (depending on where the threshold is set) could justify deferring costs to future generations (334). This idea of sufficiency is 
in relation to the current generation having their needs met to a sufficient threshold. Caney combines this with the issue of partial, or non-compliance, as I have discussed previously in the section on nonideal theory (334). Caney uses the following example:

"There are people who are desperately disadvantaged. If they do not increase their use of energy, then they will not be able to attain a decent standard of living (the sufficiency threshold). At the same time, if they do increase their use of energy by using fossil fuels in order to attain a decent standard of living, then they will make a major contribution to causing dangerous climate change. These people face a potentially tragic choice." (334).

Caney recognises the reality of the current situation globally, where many people cannot access basic necessities such as those provided by access to electricity. The emissions required for them to meet those needs will likely tip us over the permissible amount to avoid dangerous climate change, especially when we factor in partial or non-compliance by some states. Therefore, this is a difficult balance to be met. This will be discussed more thoroughly in the following chapter; however, it is important to highlight this here as it is a significant consideration when evaluating the permissibility of deferring costs to future generations. (Caney: 334).

Caney suggests that if there were a way for the disadvantaged to borrow money now and pay it back much later, they would be able to meet the sufficientarianism threshold and avoid dangerous climate change (334). Caney believes this would realise both the sufficiency threshold of his framing and that of Moellendorf's, as he states that the current poor would be able to develop, but the costs would not compromise the capacity of future generations (335). The basis for this claim is the assumption that future generations will be wealthier, but also that intergenerational sufficientarianism calls for justice across generations, not only for considering the just conditions for future generations (335). I again raise the same concerns around the certainty that future generations would be wealthier than we are, 
however, the argument around the demands of intergenerational sufficientarianism provides strong support for the right to develop and mitigating climate change.

\section{Conclusion}

The issue of intergenerational justice is significant in the discussion of obligations in climate change mitigation. We are reaching a point where even the current generation will likely see significant negative effects from the emissions of the past. However, it is future persons that will experience the worst effects of climate change.

Firstly, this chapter outlined the work of Moellendorf on the principles that could be used to distribute the costs of climate change to future generations. Moellendorf explores which principles are required and the standards we would want to guarantee for future generations. He places great importance on the fifth premise of his argument for Intergenerational Justice over Future Sufficiency. This premise provides a good guide for how to determine the living standards we ought to protect or ensure for future generations, as it considers what we would have wanted previous generations to select for us. This removes some of the time preference suggestions raised by Caney. Ultimately Moellendorf determines the just principle would be Intergenerational Equity, which acknowledges the likely greater wealth of future generations when determining how much obligation we can pass on to them.

The chapter then discussed Caney's social discount rate options. These are an extension of the Moellendorf discussion as they look to how the costs of climate change mitigation might be passed on. There are many intergenerational considerations as to how to fairly distribute the obligations across generations. Pure Time discounting may not be appropriate when considering the needs of the global poor today. Under pure time discounting, there would be little to no allowance for development in a way that is accessible to the global poor. The growth discounting proposed by Caney would be a useful 
tool for balancing the right to develop and the norm of sustainability, if properly controlled. I concluded this section with Caney's

discussion of how to use sufficientarianism to justify deferring some costs to future generations to ensure full intergenerational justice.

This provides an important limitation on growth discounting to ensure that some resources are available now to mitigate climate change and therefore provide some allowance for a right to develop, without creating an unfair burden for future generations. The next chapter will discuss how intragenerational considerations will impact the formulation of a just distribution of obligations. It will use the arguments from this chapter as a foundation for how to balance intra and intergenerational considerations for a just distribution. 


\section{Chapter Four:}

\section{Intra-Generational Justice}

This chapter will bring together the ideas from the previous two chapters to evaluate what the right to develop ought to look like. It will focus on some different approaches to distributing obligations in an intragenerational context, and how these serve to frame the discussion of the right to develop.

Developing nations have significant barriers to participation in climate negotiations. One should note the vested interest many developing nations have in climate negotiations, as it is often the less developed, low lying lands that are affected by changes in sea level rise behaviour, and economies dependant on harvests that will be affected by changes in climate (Posner and Weisbach, 2010: 11). However, this should not result in an increase in the burden to developing countries, primarily because they are unlikely to be able to afford it. Developing countries argue that they should also be able to use resources and create industry as the developed countries have done and that it would be unfair for them not to have this right and continue to live in lesser conditions (Shue, 2014: 46). There is also the understanding, set out above, that developed countries must do relatively more in the face of climate change because they are more responsible for causing it than developing countries. The "right to develop" is taken to mean that developed countries have lesser duties in relation to climate change mitigation, however, it cannot mean that there are no obligations or that developing countries can exploit natural resources to the same extent that developed nations did before them. There must be some recognition of the science and understanding of the impact human activity has on the environment and this should not be ignored for the sake of an even playing field for development. Furthermore, we must also consider the interests of future generations discussed in the previous chapter of this thesis. 
I begin by outlining an argument proposed by Peter Singer, that extreme poverty can be eradicated with minimal sacrifice through charity. This is presented as an easily achievable task. I use this work to illustrate that allowing a minimal right to develop, restricted to a basic needs threshold, would be realistic and manageable through the resources currently available.

I then discuss Moellendorf's Intragenerational Conditions where he proposes three scenarios of poverty conditions in the future, Continued Deep Inequality, Global Justice and Progressive Inequality Reduction. Moellendorf illustrates how poverty reduction now will lead to less inequality in the future and therefore greater intragenerational and intergenerational justice. Narasimha Rao has a contrasting view on the method of distribution for intragenerational justice. Rao is critical of approaches that advocate for broad state action, as he argues this has the potential to attract free-riders and results in opportunity loss due to the lack of targeted action.

I consider the work of Singer, Moellendorf, and Rao, to seek a balance in the distribution of obligations and assistance at a state level while recognising the need to address internal state inequality in order to be successful in a fair distribution. Poverty eradication, and therefore a right to sustainable development, requires states to regulate the distribution of resources within the state, but also for the international community to contribute and work collectively to ensure that basic rights are being met. Both elements are important in distributive justice, especially when we seek to justify a right to develop that can be impeded or supported at either or both levels.

\section{Singer's Charity Argument}

In Peter Singer's, The Life You Can Save, he argues that eradicating severe poverty could easily be achieved through charity. He uses the World Bank definition of extreme poverty, which is: "not having enough income to meet the most basic human needs for adequate 
food, water, shelter, clothing, sanitation, health care and education."

(Singer, 6). From this Singer presents the following argument:

"First premise: Suffering and death from lack of food, shelter and medical care are bad.

Second premise: If it is in your power to prevent something bad from happening, without sacrificing anything nearly as important, it is wrong not to do so.

Third premise: By donating to aid agencies, you can prevent suffering and death from lack of food, shelter and medical care, without sacrificing anything nearly as important.

Conclusion: Therefore, if you do not donate to aid agencies, you are doing something wrong." (15).

This argument compels those who have the ability, to assist in the eradication of poverty. Singer goes further, outlining how it is entirely possible to eradicate poverty through charitable donations, and in reality, even just a few of the very rich would be able to achieve this together. Singer clarifies that he does not want to advocate for changes in taxation, but for the ethical choice to make when using money (29). Singer examines a number of different contributions that can help to save a life, such as mosquito nets and vaccinations. From this he determines the cost to save a life to be somewhere between \$200 and \$2000 (111). Singer later uses the calculations made in 2001 by Jeffrey Sachs to illustrate the level of obligation required to eradicate poverty if distributed amongst all those who would not be “sacrificing anything nearly as important." Sachs' formulation is based on the poverty line being at US $\$ 1.25$ per day. At this rate Sachs argues that US\$124 billion would be needed to raise everyone out of poverty. He states the gross annual income for 22 OECD countries for that year was US\$20 trillion. This works out to the requirement of $62 \mathrm{c} / \$ 100$ in order to do one's fair share. Sachs illustrates with the example of someone on a salary of US\$50,000, who would need to contribute only US\$300 per year to do their fair share. (153). 
There may be some limitations to this, for instance the overall gross annual income likely includes many people who earn very little to the point where contributing 62c/ $\$ 100$ earned could be a large sacrifice. However, this model illustrates if those in the wealthy countries all contributed evenly, poverty eradication is possible and easily achieved. In accounting for those with limited means, there ought to be a larger share paid by the super wealthy, such as billionaires, who would easily be able to contribute more than $62 \mathrm{c} / \$ 100$ without sacrificing much at all. The argument from Singer illustrates that poverty eradication is entirely possible, without large sacrifices, if people chose to spend their money ethically. The level of poverty eradication is in line with the limited right to develop that I advocate for, following Moellendorf's right to sustainable development. There are reasons to limit the extent of development in order to preserve a just society for future generations, however, limited development is easily achievable and ought to be respected.

\section{Moellendorf's Intragenerational Conditions}

Moellendorf discusses intragenerational justice considerations as these relate to the distribution of costs for climate change mitigation. Moellendorf considers this an important element of intergenerational justice (Moellendorf, 2009(b): 206). In this thesis, I am trying to find the balance between a right to develop and the norm of sustainability. Therefore, in my discussion I use the points raised by Moellendorf to explore the intragenerational considerations that ought to inform the distribution of obligations, both within and between generations. Moellendorf discusses three different scenarios under which the principles discussed in the previous chapter could be applied. These are three scenarios relating to the progression of poverty conditions into the future. They are as follows:

1) Continued Deep Inequality: "assumes that although very modest gains will be made in addressing absolute poverty, along the lines of the First Millennium Development Goal, global inequalities 
and attendant severe poverty will continue for the rest of the century."

2) Global Justice: "assumes that global inequalities and attendant severe poverty are permanently eradicated in the very near future, in the time that it would take to arrive at a new international agreement on climate change and to establish the institutions for governing it. Thus, at the inception of the new $\mathrm{CO} 2$ emissions reduction regime the global order is substantially just."

3) Progressive Inequality Reduction: "assumes long-term institutional change, producing significant decreases in inequality and attendant poverty, such that by the end of this century the global economy is significantly more just than it is now." (206).

Moellendorf argues that under Global Justice conditions, the Intergenerational Equity principle would not cause any distributive injustices (220). This is because inequality would no longer be an issue: a new climate agreement could be drawn up, that would not have to account for inequalities. This scenario is highly unlikely to eventuate as we are already in need of urgent action and there is still significant inequality. How inequality is supposed to be eliminated in the near future is not discussed; therefore, it is difficult to entertain this scenario. One possible method of getting to this scenario would involve deferring as much of the costs as possible to the future, in order to invest in the current generation to provide clean, cheap energy to assist developing nations. However, this would likely not meet intergenerational justice requirements as assigning obligations to future generations without their consent, regarding problems they have not created, would be unfair. This would follow from the argument made by Moellendorf in the previous chapter: when determining the best cost principle to use for intergenerational justice, we ought to pick one that we would have preferred earlier generations had followed (Moellendorf, 2009(b): 212).

Another possibility is Singer's approach, where he has clearly illustrated that eradicating poverty is achievable and would not require huge sacrifices. Though this theory adds weight to my 
position of a basic needs threshold of development, it has been around for many years now and we still do not see the effects. The scenario is therefore unlikely to play out. It is something that we can hope will happen in the near future but is not something we should base our assumptions of the future on, especially in light of the non-ideal theoretic context we are in. Therefore, solutions under the Global Justice conditions cannot satisfy both intra- and intergenerational justice requirements, as we cannot place too much obligation on future generations through deferring costs to eradicate poverty and we cannot assume that poverty will be eradicated through the achievable levels of charity advocated by Singer.

Moellendorf argues that under Continued Deep Inequality there is an expectation that whatever options are selected inequality will continue. The concern regarding this scenario is whether mitigation costs would compound injustice on the poor. For example, if costs are deferred to future generations, one might find that these additional costs in the future fall more heavily on the future poor. On the other hand, by deferring to future generations, some other future povertyrelated costs might have been avoided and therefore this approach could be beneficial to the poorest peoples across generations (220). I find this latter argument persuasive since the poorest nations are the ones who will likely experience the worst effects of climate change such as sea level rise, drought and flooding, and that urgent action is therefore required to prevent long-term harm. (Moellendorf: 220). However, this scenario is not one that we should base our distribution on, as a truly just solution must look to alleviate poverty. It is unlikely that climate change can be globally addressed without some element of poverty alleviation. Not only because it would be constructive to address poverty, but because growing economies will likely pollute more and therefore, finding ways to equitably distribute clean energy resources would be beneficial for the common goal of climate change mitigation. Furthermore, a just outcome must look to find an equitable outcome for all, and if poverty is not addressed, regardless 
of action against climate change, it cannot be considered a successful program if there are significant losses among the less advantaged. Moellendorf concludes that the principle of Intergenerational Equity would again be favourable under this condition as it would lower some of the adaption costs in the present, therefore contributing to the lowering of inequality in the present (221).

Moellendorf expects Progressive Inequality Reduction to raise a number of other concerns. He considers any distributions under this scenario to be unjust because they are assigned under conditions of injustice. The poor will be disproportionately affected by the costs of future mitigation, and although this may also be relevant to Continued Deep Inequality, the distribution of costs under Progressive Inequality Reduction will likely be more aligned with justice because of the progression to reduction of poverty. Under this scenario, the costs for the present generation of impoverished may be more than future impoverished individuals, even if the costs are proportional to the population. Moellendorf proposes two reasons for this. (Moellendorf: 221).

Firstly, there will be a smaller percentage of the world's population that is severely impoverished in the future and secondly, a just distribution will be less likely to compound injustices that are present (221). Therefore, though the absolute costs, and even proportional costs, may be more, it would be caused by the reduction in injustice and extreme poverty. The Progressive Inequality Reduction scenario is the most appealing of the three scenarios as it appears to be feasible. Though we would ideally like to have a Global Justice scenario, which we know would be possible from the work of Singer and Sachs, it has failed to eventuate as yet. The Progressive Inequality Reduction scenario is one in which long term change is made, though perhaps not at the speed we would desire. If we must balance the norm of sustainability and the right to develop, this is the most likely scenario that we would follow. It ought to enable basic needs development to be a priority, but beyond that development would 
need to occur in a sustainable manner, that preserves the rights of current and future generations.

Moellendorf also discusses potential opportunity costs that occur due to the commitment to reduce severe poverty. He states that current expenditure on mitigation costs are lost opportunities to spend on the reduction of current severe poverty. Moellendorf argues that if parties were deciding under the scenario of Progressive Inequality Reduction, they would still likely pick Intergenerational Equity as their guiding principle, placing equal proportional burdens on generations which have unequal proportions of poor people. Using the criterion that one should choose as one would have wanted previous generations to have chosen, the burden would be heavier for the current generation, who will be poorer than future generations, in order to reduce the costs for the future generation. There would be opportunity costs to the current generation who, due to the higher mitigation costs, would miss opportunities to address inequality in this generation. This inequality might lead to future inequality, which, if we are considering the best option that we would have wanted previous generations to have selected, we would want to avoid. Moellendorf concludes that under Progressive Inequality Reduction, it is difficult to determine which principle should be followed if we do not have more detail about the context and the actions taken. (Moellendorf: 221).

I find this scenario significant for the discussion of intragenerational justice because it involves greater consideration of the position of the least advantaged in the present and how this could impact future equality. Although Moellendorf argues that any distribution under this scenario would be unjust, I find this to be the most realistic scenario for the current situation. In this non-ideal context, Progressive Inequality Reduction reflects the reality of the situation and though it is an unjust situation, it can be used as a foundation for determining how to determine the most just solution in these circumstances. The principle questions how future poor would be affected by decisions 
that would either prioritise mitigation or present inequality reduction. This is significant for the developing and developed country distinction. Many developing countries are looking to develop to help get their poor out of poverty and grow their economies. If there is an opportunity for them to put more effort into developing to aid their impoverished people now, they will likely experience less inequality in the future. In climate negotiations, consideration often does not extend this far, and it is seen as a battle between protecting people today compared to protecting people in the future. In the context of climate change, the protection of future people involves people across the globe and those in developed countries will also feel the effects.

However, it is important to remember that the impacts of climate change will first affect the developing world. Inequality will grow significantly as severe climate events increase in frequency. The right to develop needs to be incorporated into any climate decisions as inequality now will only be extended into the future. However, unlike in many scenarios, this is not an either-or exercise, and immediate action on climate change is urgently needed. If action is not taken there will be two significant repercussions that may counter the right to develop. Firstly, severe climate events will render action taken to reduce inequality redundant as people will struggle to adapt. Secondly, if the climate goes beyond the theorised tipping point of two degrees Celsius (perhaps even 1.5 degrees) then living conditions will be significantly diminished. Regardless, it is clear that some form of a right to develop ought to be incorporated in climate agreements if they are to be just, and the inclusion of this right will likely lead to a more just future as well.

The importance of this discussion is that mitigation of climate change today will impact the current generation and every generation; there is not a sharp divide between the effects for the current and future generations. Climate change, as a global problem, will impact everyone eventually, however, it will affect the poorest first. Investment in infrastructure and access to resources could 
significantly improve the chances of survival for these people and therefore increase the likelihood of greater equality in the future. If these actions can be taken now, they can provide a means of survival, and then further measures can be taken to address the climate. Realistically, both development and climate protection could be achieved with greater information and resource sharing across countries. In the scenarios discussed by Moellendorf, Progressive Inequality Reduction is the most promising and useful in a discussion that attempts to balance a right to develop and the urgency of protecting the environment. Progressive actions towards reducing inequality will likely reduce future inequality which ought to be the aim of international agreements that portend just solutions to global issues. If this is not the case, there would be little motivation for developing countries to participate in these types of agreements and the chances of success would be significantly hampered.

It is clear then, that the needs of the present generation must also be considered, and this is important for both intra- and international justice as the impacts of present inequality will likely be echoed in future contexts. Taking equality as a goal for future agreements, an ability to pay approach would be well suited to the task of climate change mitigation principles. It would look to who can afford to pay and would allow states that need to focus on internal development do so without being excluded from the international negotiations. Using equality as a motivation behind the distribution of obligations might also remove some issues around the lack of accountability for previous emissions which is a criticism of this principle. If we are aiming for an equitable outcome for present and future generations and the ability to pay principle can achieve this, countries ought to contribute, as they are able, in order to achieve the goal and create equality through generations.

\section{$\underline{\text { Rao's Intranational Justice }}$}


Narasimha Rao discusses the need to allocate obligations beyond merely the state-level that Moellendorf appears to consider, to ensure a fair distribution through targeted implementation policies. This is an important distinction, as the intranational context can significantly differ from the state level context. This is particularly the case with emerging economies. In Rao's paper he discusses the potential for free-riders and lost opportunity due to the lack of targeted burden sharing systems. Rao states that the least refined burden sharing approach is one which assumes that all states should bear the burden equally, without taking into account the needs of developing countries. (Rao, 2014: 134).

Rao also recognises, however, the difficulty in getting political agreement around the differentiation of obligations. He suggests two reasons for this; firstly, because of the financial incentives that influence internal policy making, and secondly, because of difficulties in objectively creating emissions pathways for the global poor. Rao highlights the connection between benefiting states ${ }^{2}$ policy and the number of global poor. Rao continues, stating that many writers on distributive justice agree with, "[t]he notion that people below a certain threshold of well-being should be exempt from mitigation burdens." This distributive exemption is stated as follows: "up to a certain threshold of entitlement-however defined — people ought to be exempt from any substantive mitigation obligations for which they are not compensated." Rao argues that the appeal in the principle is that people should be able to fulfil their basic rights, and mitigation obligations ought not interfere with that ability. (Rao: 134).

Rao outlines a system that relies on a baseline of income as a mechanism for determining the distribution of obligations going forward. He states that the distribution must depend on "the number of poor below this threshold, their income, and the carbon intensity of their income." Rao states that in the next two decades, which he

\footnotetext{
${ }^{2}$ I will generalise and refer to these as developed states.
} 
suggests is the crucial time period to stabilise emissions, there will still be a large number of poor who live in poverty. Rao argues that the "rate and distribution of growth" will be an important element for determining the distribution of obligations now and in the future. This is because future growth could reduce the amount of emissions exemptions that need to be made - because if more people are out of poverty there will be fewer people to include in any exemption or limitation of obligations. (Rao: 135)

Rao presents the following hypothetical to illustrate his point:

"Consider a hypothetical burden-sharing arrangement between two countries, an Annex I country (A1) with no poverty and a non-Annex I country (NA1) with substantial poverty, which includes a commitment to exempting the poor from mitigation. Suppose they assess their respective responsibility to exempt the poor based on their aggregate income share above the poverty threshold (e.g., \$15 trillion and $\$ 2.5$ trillion, for a poverty threshold of $\$ 9 /$ day). 12 Suppose that NA1 has 500 million tons of CO2eq below the threshold in 2015 and is required to reduce emissions by $30 \%$ below businessas-usual ("BAU") in 2020. NA1 can follow two "baseline" development trajectories for the next decade, $\mathrm{A}$ and $\mathrm{B}$, with the same average GDP growth, but different internal emphases in development. In A, rural development is emphasized and the state pursues an improved biomass cook stove program that benefits the poor's development and reduces the carbon intensity of their consumption. In trajectory B, rural development is neglected and the rural poor shift to modern, carbon-intensive fuels. Trajectories A and B lead to aggregate emissions of 250 million and 350 million below the poverty threshold. The costs that A1 would bear to exempt the poor in the two scenarios, $\mathrm{A}$ and $\mathrm{B}$, would be $\$ 2$ billion and $\$ 3$ billion, with a mitigation cost of $\$ 35 /$ ton.” (Rao: 135).

Rao notes that this is relevant for the growing number of "emerging" economies, which have substantial income but also a large number of poor people. The poor population has relatively high emissions and they would therefore be entitled to access to resources due to the 
exemption of the burden on the global poor. The fact that they also have wealthy members of the state would mean that other parties to the agreement would be reluctant to assist, as those wealthy members of a state like NA1, ought to contribute to the welfare and development needs of their state's poor. (Rao: 135).

This is an interesting discussion as it highlights issues surrounding the support and exemptions that ought to be considered when distributing obligations. Wealthy states such as A1 may be required to assist less wealthy states, like NA1, however, consideration ought to be made regarding the distribution of wealth within that nation as well. In mitigation action, current agreement is at the state level and therefore there may be challenges in gaining consensus when states know that more could be done to alleviate poverty within a state, rather than accessing finances from outside the state. If a state like NA1 can select between the options presented in the hypothetical above, it would seem they ought to select option A.

The goals of international agreements are often reduced to numbers rather than actions and this can hide the truth of the actions states are taking. This can distort the perceptions of what a fair and just distribution ought to look like. A just distribution of obligations ought to also consider equity within states. In particular, there may be many people in developed countries that are not as well off as some people in the emerging economies. It would not be just if the former were subject to policies that limited their ability to grow. However, it would be extremely difficult to organise policies to this level of applicability. In general, there are certain trends that can be accounted for, and it would then be up to the individual states to determine their internal policies to ensure a just distribution of obligations at that level.

This discussion has mainly focused on the large exceptions of emerging states where it would be problematic to treat them as being either wealthy or poor exclusively. It is an important element of the 
discussion on climate change mitigation obligations as the largest emerging states are China and India who are responsible for a sizable proportion of global emissions. These ideas could be problematic for a right to develop, as they further complicate the matter by recognising the lack of a clear divide between the developed and developing worlds. This can also be problematic for a utilitarian approach to climate change mitigation due to the fact that, on absolute terms, China and India have a greater number of impoverished people than many other developing nations (136). This would therefore lead to the conclusion that they ought to be given more resources and afforded larger emission budgets, but this does not account for the huge concentrated wealth within the country. This is also reflected in any "per capita" approach to emissions as this would disproportionately benefit these large emerging economies.

\section{Conclusion}

It is clear that there are obligations that are owed to future generations, but also current generations, and in order to get the balance right a precautionary approach must be adopted. Considering Moellendorf's scenario of Progressive Inequality Reduction, there are several aspects to the discussion that need to be determined. In order to determine how to distribute obligations one must consider the current position of the least-developed nations, and some developing countries, that will be heavily affected by climate change and will have little hope of reducing poverty into the future if they do not receive some help. On the other hand, if too many resources are devoted to developing a scenario that reflects Moellendorf's Global Justice, there would be little hope for achieving justice for future generations. The question is a difficult one because of the uncertainty that surrounds the impact today's actions will have on the future. Uncertainty plagues the climate discussion and it is important not to become paralysed by this. The balance between future and current generations must be achieved to the best of our abilities in the present. 
The considerations raised by Rao are also important in my discussion of obligation distribution as they raise concerns regarding the best method of distribution. Accounting for the inequality within nations would also be an unavoidable task for any distribution method. Though it is not the primary focus, and perhaps state sovereignty and other autonomy rights ought to be respected, there is vast inequality in many of the "emerging states" which are often classed as developing and in need of assistance. These outlier states can raise difficulties in distribution as they have both extreme wealth and extreme poverty. It would not be just for these states to receive vast amounts of support (sometimes from states that could use the resources to alleviate inequality in their own countries) if there is no mechanism to ensure the resources are assisting the global poor and not merely growing the economy. As mentioned in Chapter Two in relation to partial and non-compliance, sometimes the motivations behind state actions can influence the permissibility of those actions.

I want to make clear that the basic needs right to sustainable development advocated by Moellendorf is one that ought to be respected. Anything beyond this right is hard to defend due to the points made in Chapter Two, but also from Rao's argument, where it is clear that states do not always comply with the demands of justice. Rao's discussion therefore offers an important additional consideration to those raised by Moellendorf regarding how to best distribute obligations within the current generation.

The just outcomes for current and future generations have a strong link, as reductions in inequality now will likely lead to reductions in future inequality, but only if it does not exceed a safe level that protects the environment from collapse. If we allow a right to develop that is unlimited, this would require the use of an unfair share of available resources from an intergenerational perspective. This would likely lead to greater inequality due to resource scarcity. With current knowledge, it is unconscionable to exploit resources to develop as was done in the past. Beyond the basic needs threshold proposed by 
Moellendorf discussed in Chapter Two, there may not be large allowances for a right to develop. 


\section{Chapter Five:}

\section{Potential Solutions and Future Leadership}

In this chapter I will examine some potential solutions to the threat of harmful climate change, and also discuss leadership in climate change mitigation. These elements are an important aspect of the discussion of distributing obligations in a manner that respects both the right to develop, at least to a basic rights threshold, and the norm of sustainability.

I begin the chapter by discussing the issue of leadership in international negotiations around climate change mitigation. Henry Shue suggests there is a lack of leadership, stating that many countries are waiting for someone else to take the lead (Shue, 2011: 22). There have been promising signs that states are now wanting to take the lead, as climate change effects become more prevalent and the potential benefits of leadership, especially in innovation, become more evident. However, the very notion of a global leader is problematic. For all the potential concentration of power, the leadership that is arising in the international climate change context is providing hope that real change is happening. Significant changes are being made, including commitments to electric cars and the switch to renewables. These changes in leadership are already part of the solution, however, I also examine the emissions trading scheme, which I believe is not a suitable aspect of current proposed solutions.

In the second part of this chapter I discuss the emissions trading scheme and argue it is not an appropriate tool for creating a significant impact on emission reductions. I use the work of Jonathon Aldred to support my claim as he argues that emission trading schemes maintain an unjust status quo. I also discuss Simon Caney's argument that the emissions trading scheme is not inherently untenable, but the current formulation is not working. However, I 
believe that there are better means of achieving reductions in emissions that could potentially create even greater benefits which should receive our focus instead. Sharing of resources and access to resources would be a much more efficient way of allowing development that would not negatively impact the climate. If technology was shared and finances provided, the least-developed, and developing states would be able to access and implement clean development. This would then meet their basic needs and has the potential to go further towards what the developing states truly want, equality.

Finally, in this chapter I discuss David Miller's “outcome responsibility" which I first raised in Chapter One. I argue that focusing on outcome responsibility, in the context of an ability to pay approach, would significantly improve participation and action in climate change mitigation. Those who are responsible for the outcome ought to contribute to the solution, but also those with the ability to pay can also assist in providing fast access to resources that will protect current and future generations. This would also connect with the idea of sharing resources and other means of support for developing nations to develop in a way that does not impede the norm of sustainability. In this way we can balance the right to sustainable development and the norm of sustainability, by ensuring the resources needed to develop are clean, renewable resources that are sustainable and good for all generations.

\section{$\underline{\text { Leadership in Climate Change Agreements }}$}

There is some hope for the future as countries are beginning to acknowledge and act with greater intentions of reducing emissions (Light and Taraska, 2016: 177). With the notable exception of the US, it appears as though many are opting for the second approach to noncompliance and continuing with the same goals, however, there are also indications that some are willing to do more. There has also been an increase in the effectiveness of non-state actors who have 
influenced and contributed to climate mitigation efforts. For most states the priority has been, and continues to be, economic growth (Shue, 2014: 103). This causes tension with climate action as, especially in situations where there is non-compliance, it becomes more of a burden for other states to continue with their obligations. This has been thoroughly argued by Henry Shue in his article "Face reality? After you! - a call for leadership on climate change" (Shue, 2011). Shue argues that everyone is waiting for someone else to take the lead and that this actor will likely have to suffer an initial loss to do so (Shue, 2011: 22).

However, it is evident that leadership in climate action is becoming a more contested area, with several countries promising big actions, such as eliminating the sale of petrol cars or promises for renewable energy production. In the few years since Shue published his paper, there has been a shift in attitude towards climate change. There appears to be greater recognition of its impacts and potential to destroy and therefore action has become more urgent in the international community. Though Shue's point on America's lack of involvement still stands, other big polluters such as China and India have become major players in the drive for climate change mitigation. Shue also critiqued the inefficacy of international agreements with voluntary standards and lack of enforcement (Shue, 2011: 23).

Though there is greater interest in being the leader of climate change discussions, will this leadership assist in creating a fair distribution of obligations? All states must participate in climate change mitigation. Contrary to the International Paretianism that Posner and Weisbach advocate for, there is condemnation for those who do not. However, the condemnation does not go beyond expressions of disappointment and frustration. Perhaps a leader would be better able to unify states in order to apply pressure to those who do not wish to do their fair share. But who would be that leader? Much like many other discussions of global leadership, there are legitimate concerns about the concentration of power. This would be a pressing concern for 
states, especially in relation to their obligations under such leadership. Developing states may be reluctant to appoint a leader from a developed state as it is likely that any states will look out for themselves and perhaps limit the obligations arising from historic emissions. Similarly, developed states would not wish to take on large burdens as discussed above, and as mentioned previously, there may be little justification for doing so.

A partnership, with leaders of both developed and developing interests may be a reasonable option that would solidify leadership and unification without the doubts that may arise from a single leader. A partnership would allow the leaders to monitor and assert the obligations of developed and developing states without necessarily dividing along these lines. A distinction could be made between the poorest and wealthiest nations, or perhaps most appropriate would be a distinction between both developed and developing, wealthy and poor nations in order to have the biggest impact with the fairest distribution. When applying the considerations raised by Rao, it will also be important to ensure that support provided by the international community goes towards the global poor, distinguished from the more collective idea of the poorer nations. Having leaders representing these interests would limit the negotiation time and excuses that arise when all leaders have their say in these discussions. The distribution of obligations could therefore be achieved with higher goals than may otherwise have been reached.

There are doubts that remain about concentration of power. In relation to the power to determine legal or treaty obligations to mitigate climate change, these doubts are strong with significant implications. If states cannot trust those who represent them, they will not agree to obligations. States might feel that their situations were not considered, and the obligations placed on them were unduly harsh. This has been the motivation between UN agreements on climate change allowing all leaders to voice their concerns and develop goals that are workable for their states. We have seen this is a flawed approach, as many 
states are doing much less than what is needed for effective climate change mitigation, but also much less than what they are capable of. Leaders would provide some objectivity in the distribution of obligations, while also demonstrating by example that it is possible to meet these obligations without stalling economic growth.

It was difficult to imagine that this process could work a few years ago, but there have been some very promising signs. The promises and obligations voluntarily adopted by emerging economies such as China have shown an understanding of the scale of the problem and an intention to meet the challenge while still providing for their people through their pledges under the Paris Agreement 2015 (Knopfe and Kejun, 2017). Many European countries are leading the way for developed countries with promises to move to green cars and adjust their lifestyles (Chrisafis and Vaughan, 2017). These countries are beginning to show that it is possible to adjust lifestyles and reach climate goals. However, it is important to note that these countries are at the top end of the scale for their respective types of state. Many developed nations will not have the infrastructure or means to implement the lifestyle that Scandinavia has. The situation is the same for developing countries in comparison to the large industries and wealth of China.

The limitation of a right to develop is important in order to keep perspective of the achievable standards that can be justified in balance with the norm of sustainability. This is especially the case in relation to the speed at which development is desired. It is unrealistic and unjust to allow for full scale, fast development if this cannot be done without the vast exploitation of non-renewable resources. Many of these states are those with the least ability to pay for mitigation or adaption to the impacts of climate change. If some of these nations can move to environmentally friendly practices and form partnerships with wealthy states to gain access to green technology, then there would be an identified pathway for states to succeed in climate 
change mitigation and raise the potential for further clean development.

\section{Potential Solutions}

What is needed is new ideas for how to fairly distribute obligations that allow developing countries their right to develop but do not go too far in holding developed countries responsible for "climate debt". In this section I put forward my proposal for a fairer system, replacing the emissions trading scheme with an approach that works for all parties, not just the rich, and also implements some outcome responsibility in order to balance obligations between parties.

i. Emissions Trading Scheme (ETS) - how to encourage compliance The Emissions Trading Scheme (ETS) illustrates one of the largest flaws in the current approach to climate agreements. The idea of ETS is to ensure efficiency in pollution by creating a market for "credits" which can be bought by countries that are large emitters to offset their emissions and sold by countries who do not need them, therefore increasing their ability to invest in clean energy or continue with their good practice (Posner and Weisbach, 2010: 41). There are two significant flaws in this system I wish to address here. Firstly, there is a general concern that the ETS is not working towards the overall ideal goal of climate agreements, as it maintains essentially a status quo (Aldred, 2016: 149). The second flaw is that ETS further inhibits development for developing countries. These states do not have the money to buy credits and would be incentivised to sell their credits to wealthier, generally developed, countries, thereby inhibiting their own development.

The first concern has been thoroughly discussed by Jonathon Aldred in his paper, "Emissions Trading Scheme in a 'Non-Ideal' World" (Aldred, 2016). In this paper, Aldred argues that ETS does not work towards the ideal goal as it inhibits innovation. Though Aldred accepts that there may be an incentive to reduce emissions in order to 
sell credits, he argues that the buyers of credits will continue to buy them when they are available. This is because it is often cheaper to buy the credits than it is to innovate. Aldred argues that the ETS is a short-term solution, when we are addressing a long-term problem. (Aldred, 2016: 151-153).

When countries and companies can buy solutions to environmental issues rather than working on improvements for the future, this severely limits the production of innovative solutions, as these wealthy elite are necessary funders of the new technologies required. Though ETS makes sense in the short-term, it does not contribute significantly to the overall ideal goal of reducing emissions completely. Including ETS in climate agreements is often a farcical way to include states with little intention of changing methods of production as they have the power and wealth to buy the lifestyle they desire. This opportunity to buy a particular lifestyle highlights the inequality present between developed and developing countries.

This leads into the second criticism of the ETS in climate agreements, the imbalance in bargaining power between developed and developing countries. Systems such as ETS have a tendency to enforce the norms of economic status. Richer countries can buy their way out of trouble, while poorer countries are forced to change their ways to comply with regulations as they cannot afford fees, nor can they afford the mechanisms to continue without innovation. However, in most cases they cannot afford the innovation either, leaving their progress stagnant. The idea behind ETS is that poorer states would at least get some capital to put towards their development. However, in reality, they must be receiving less than it would have cost richer countries to innovate, otherwise rich states would innovate rather than buy credits.

This structure does not allow for an even and fair society as wealthy states can control and grow at the expense of poorer states, while appearing to support them through payments. Wealthy states are 
therefore not required to invest in new technology or share this technology with developing states, but rather merely buy out the poorer states with what appears to be a large sum but in reality, cannot sustain the people of those countries. This injustice further illustrates why current systems are often inadequate for the purposes they wish to achieve.

Caney suggests that though there are flaws in the way ETS are currently operated, this is not an inherent flaw in ETS themselves. Caney has a potential response to the second criticism I have outlined above. He argues one of the motivations behind this criticism is the idea that every person should do their part, and not pay others to do the work for them. The application to climate change is that each state should lower their emissions, and not be allowed to pay others to do this instead. Caney suggests that this criticism arises from the idea of civic duty, that one ought to do their part in civic society and those responsibilities cannot be bought or sold. Caney argues that this civic duty idea can be accommodated with a form of emissions trading. The idea of emissions trading is to reach an overall goal. Caney suggests that the value placed on civic duties arises due to the performance of the task - if this task can be bought or sold we do not have reassurance that it would be effectively performed. Therefore, Caney states that this is not directly applicable to ETS as there is no integral requirement that the duty to reduce emissions be performed by particular actors. (Caney, 2010(b): 203-211).

Caney also raises an alternative approach to ETS, proposed by Oliver Tickell and Peter Barnes. Their approach promotes an upstream auction. This is the idea that emissions permits are sold to the highest bidder and the revenue gathered is then distributed. This approach has two strong benefits. Firstly, it promotes a form of the polluter pays principle, as those who wish to emit must pay. Secondly, it raises revenue which can be spent in ways that improve justice, for instance on mitigation strategies and adaption measures. Caney discusses the concerns around this approach, especially in relation to the disparity 
between the wealthy and the poor. A potential solution would be to use the revenue gathered from auctioning the permits to help the least advantaged. (Caney: 214-215).

Caney offers one further defence of ETS, which in my view is most effective as a non-ideal context solution. This is the idea that for ETS to be an effective solution, it merely needs to contribute to lowering emissions as part of a wider range of solutions that together address the necessary reductions (216). Caney uses the following example to illustrate this point. Imagine:

\footnotetext{
"a scenario in which the best viable option is a mitigation programme which contains policies a, b and c. Suppose, though, that policy a does not actually lower emissions but that it is a persuasive sweetener and that powerful actors sign up to the package as a whole only because it contains policy a. Then, other things being equal, it would be wrongheaded to reject policy a even though it does not itself lower any emissions." (216).
}

This is therefore a suggestion of ETS as part of a non-ideal solution to both assist with getting more countries on board and also to offer some, though perhaps not significant, reductions in emissions. Though in this thesis I advocate for non-ideal solutions, and Caney has provided an example of how ETS suits the non-ideal context, I do not think this means we must accept a status quo approach. I agree with Caney that there is perhaps nothing inherently wrong with ETS, but there is something wrong with the current model we are using. I suggest alternative solutions that have the potential to achieve more than a scheme that currently maintains a status quo and does not have the scope to achieve much more.

I suggest that we ought to shift from a punishment focus, where credits are bought to avoid public reaction or agreement repercussions, to a rewards focus. This could be done by awarding extra credits for the development and sharing of green technologies. 
This could incentivise investment in innovation, while simultaneously allowing for some emissions to continue through the transition. This may initially be unsatisfactory for the ideal goal, however, once green technologies are developed, and the money has been invested in innovation, there would be a strong desire to use the new technology and create a positive public image. Aldred has suggested that fear of public prosecution on environmental matters is a bigger motivator than financial penalties (Aldred: 161). This could be an effective solution as it would reduce the ability of countries to continue emitting large amounts while deceivingly meeting their targets. It would also be beneficial to developing countries who would be able to have a larger share of possible emissions (within reason for the ideal goal) and also receive and benefit from new technologies. It is important to keep emissions to a minimum, even if there was room within the budget of emissions. A significant flaw in the current system is that the emissions budget is calculated on what maximum limits can be applied. However, maximum limits are often based on agreed mid-range estimates, not on the extremes. This is because there would be no reasonable way for countries to adhere to limits required by the most extreme estimates of behavioural change, partly because of the efforts made to get consensus, and partly due to the desire for countries to continue to develop and not be limited beyond what is deemed necessary.

Caney suggests that there may be ways to achieve this goal which would be more agreeable to developed and wealthy states. This would be to allow states to borrow money to purchase green technology with payment to occur at a much later date (Caney, 2014: 334). This would bring in considerations of intergenerational justice, such as how much debt a country can commit its future generations to. Also, as mentioned previously, this idea would be based on the assumption that future generations would be at least as wealthy if not wealthier and therefore better able to pay the debt. This is still a promising compromise that may have scope to be incorporated with a range of 
other solutions in order to limit the debt created and maximise development to bring developing states to a certain threshold of wealth. This would initially have to be the basic needs threshold of Moellendorf's right to sustainable develop, but it would allow for the desired speed of development. This would also potentially take developing states beyond just the basic needs threshold. Rao suggests a similar approach, with the sharing of technology and the transfer to low-carbon economies (Rao, 2014: 144). Rao suggests approaches like this would be more appropriate than lowering the targets for developing countries (144). This would therefore be another means of balancing the right to develop, by providing resources for development, while maintaining sustainable practices that act to mitigate climate change.

The recent extension of the climate fund from the Paris Agreement signalled a greater recognition of the collective nature of climate change challenges and the collective action needed to solve it. Perhaps, there can be either financial or technological investments that will satisfy this requirement of the agreement. In this way, where there has been investment in technology, the technology can act as payment rather than a financial contribution. Innovation is a central element that will determine the success or failure of collective action against climate change. As we have seen, the development of electric cars has increased exponentially, with many states setting targets for the end of sales of all petrol and diesel cars. Sometimes, information need not even be shared widely for a significant new idea to spread through the markets and force a change in habits. This is what is required for effective climate change mitigation. Agreements need to reflect these requirements and include provisions for greater innovation and reduce incentives for minimising compliance.

ii. Outcome responsibility and Ability to Pay

An issue that needs to be addressed further arises from the above discussion, namely, how do we allocate obligations on developed 
countries to share their resources with developing nations? As the discussion above suggested, the distinction between developed and developing obligations in climate agreements may be somewhat misguided, due to the inequalities within large emerging economies. However, there are still some grounds to continue with the distinction in order to achieve the fairest result. This distinction must be adjusted to address the issue of the real position of states now, regardless of their previous actions or inaction. The focus of future agreements should be on how collective action can achieve the ideal goal of significant reductions in emissions, with due consideration to nonideal elements. The focus should shift away from blame and punishment and towards responsibility and rewards for positive action. Responsibility ought to include a degree of outcome responsibility to acknowledge the advantage gained by previous resource exploitation.

As discussed previously there are many difficulties in determining how significant resource exploitation was, and how responsible states may be for that exploitation. However, I have already previously suggested that there could be an application of outcome responsibility to reflect the fact that states, particularly developed states, have exploited resources and are in some way partially responsible for the current situation. I referenced the work of Miller in Chapter One, in relation to climate debt and historic emissions. Miller uses the work of Tony Honore to define outcome responsibility as follows:

"When we say that an agent is outcome responsible for the consequences of her action, we are attributing those consequences to her in such a way that, other things being equal, the resulting benefits and burdens should fall to her." (Miller, 2004: 245).

Miller continues, stating that if harm results from an action that the agent is responsible for then there may be a requirement to compensate for the harm caused (245). This is therefore relevant to the case of climate change because there can be a requirement for compensation due to the harms caused by previous emissions. 
Outcome responsibility only holds agents, or in this case states, responsible for actions which they had some control over. It is not merely that one participated in an action, but that the outcome was caused in some way by the state. However, it must be the case that, as many of the agents who caused the outcome are gone, those in the present generation who we wish to hold liable must be allocated responsibility based on the benefits they have received. Miller states that the purpose of outcome responsibility is normative, it is a guidance mechanism for where the consequences of an action should fall, but only in relation to actions which we have some control over (245).

Importantly, Miller notes that people cannot escape outcome responsibility if "through ignorance they failed to anticipate the results of their actions" (245). This is particularly relevant to the discussion in Chapter One about lack of knowledge. It is perhaps unfair to hold responsible those who did not know, and had no way of knowing, that their actions would have a negative effect on the environment. However, emissions did not cease or slow after this knowledge became available. From this point we can attribute outcome responsibility on all states that continued to emit, or increased emissions that have contributed to climate change and harm to developing nations. ${ }^{3}$

Alternatively, one could view outcome responsibility as a means of denying any historic responsibility, as perhaps the consequences of the actions could be too remote to be included. It could be argued that, though many states knew they were damaging the environment, they did not know that this would cause significant harm to the leastdeveloped and developing countries. This is a difficult argument to make as the science has been clear for decades that the level of emissions would have a significant impact on the environment.

${ }^{3}$ Here I am assuming that states will be the relevant agents, and therefore I also assume a form of collective responsibility. 
Furthermore, I would argue that this situation would fall into the scenario of having, through ignorance, failed to anticipate the consequences of their actions.

Miller continues, stating that outcome responsibility is not as stringent as moral responsibility, which is relevant to assignment of praise or blame (246). This is important as there are fewer hurdles to jump in order to prove outcome responsibility over moral responsibility. However, returning to the first point, there is a benefit in not attributing blame in the climate change context. This approach will limit the confusion and uncertainty of historic responsibility and can instead turn to obvious instances of outcome responsibility which will not be a difficult task. When combined with an ability to pay approach, which ensures that those states who are emerging economies or have recently reached significant development, there would be a greater pool of resources to assist in the clean development of other states.

Previously, I mentioned that for quick development, fossil fuels are still the most cost-effective resources to use. However, technology is quickly becoming cheaper and with greater international cooperation there may be a way to balance both the right to develop and the norm of sustainability. It will likely be a slower path, but one that is justifiable and respects both intra- and intergenerational justice. Furthermore, by combining the ability to pay with outcome responsibility, there is some recognition of historic responsibility which addresses one of the significant criticisms of the ability to pay principle. I believe these two concepts work together to achieve many of the aims of other distribution principles discussed in Chapter One. Firstly, as I discussed, ability to pay will likely encapsulate the aims of the beneficiary pays principle as most of those with the ability to pay are often those states who have benefited from past emissions. Outcome responsibility addresses the polluter pays principle, arguing that those who caused the harm should have a part in remedying the wrong. I believe all of these elements are essential in creating a just 
distribution. However, I argue that combining the ability to pay and outcome responsibility concepts will better address the goal of balancing the right to sustainable development and the norm of sustainability. This combination allows for a higher chance of success, especially in a non-ideal context, without ignoring the important considerations that ought to be made when obligations are distributed.

These principles would allow for a just distribution where the leastdeveloped and developing countries would have the smallest share of the burden, allowing them to develop and raise living standards. Initially, this will still need to be to the basic needs threshold in order to ensure intergenerational justice is respected, but the combination of these principles has the potential to reach beyond that threshold after some stability is reached. The shift from a blame-based approach to one that acknowledges responsibility creates a more positive obligation. It is a just outcome for those responsible for the problem to shoulder greater obligations, while the ability to pay ensures the urgency of climate protection is addressed.

\section{Conclusion}

There are some suggestions here of approaches that could be utilised in international agreement that would balance the many considerations discussed in this thesis. There needs to be a just distribution of obligations which balances the norm of sustainability with the right to develop. The use, exchange and distribution of green technologies emerges as a significant mechanism to achieve the desired balance. There are several means of implementing a just distribution which would require further detail to fairly distribute the costs within and between generations.

Furthermore, the shift in focus from blame to responsibility, combined with an ability to pay principle, appears to be a promising method of distributing obligations that reflects the justice considerations discussed throughout this thesis. This combination 
approach would therefore account for some historic injustice without placing an unfair burden on states that cannot afford it. The approach would also ensure the cooperation of states as there would be limited scope to avoid obligations by denying historic responsibilities. This would therefore be satisfactory for inter and intra generational justice as it would not place heavy burdens on the current or future generations through severe limitations in development or sustainable practice. The reality of the situation however, requires that both elements must be limited to an extent in order to balance the benefits and obligations experienced by states, we cannot assume full compliance and that must be taken into consideration when assigning obligations and granting allowances for a right to develop. 


\section{Conclusion}

In this thesis I have argued that there is a conflict between the right to develop and the norm of sustainability. I have suggested how we ought to balance these concepts in order to create a fair and just outcome in distributing the obligations to climate change mitigation between the developing and developed states, and between generations.

I began the thesis by exploring the distribution principles used in climate negotiations and determined that the ability to pay principle was the most appropriate for the aim of balancing the above concepts. The ability to pay principle features many of the benefits of other principles, such as the beneficiary pays principle, as those who have the ability to pay are often those who have wealth from previous emissions. The ability to pay principle also ensures states that have fewer resources are not under a disproportionate burden and it can therefore assist with allowing a right to develop.

I used Moellendorf's conception of a right to sustainable development to place an important limitation on the right to develop in order to achieve a balance with the norm of sustainability. It is clear we cannot advocate for an unlimited right to develop under the current circumstances of partial and non-compliance. In this non-ideal context there must be restrictions in order to preserve intergenerational justice. The right to develop that I advocate for is therefore, the right to develop to a basic needs threshold. This is required by the demands of justice, is not a high threshold, and can be met under current circumstances.

This becomes the foundation for my discussion of intergenerational justice, considering whether we can discount the costs of mitigation today to future generations who will likely be wealthier than we are. Using Moellendorf's principle of Intergenerational Justice, considerations of both current and future generations can be made 
when determining the best distribution. Caney's discussion of future sufficientarianism creates a justification for passing on some of the costs to the likely wealthier future generations. I have doubts about the validity of the assumption that future generations will be wealthier, but agree that under sufficientarianism there would be allowance to pass on some costs to future generations. In this way we could fund the more expensive, clean development for the leastdeveloped and developing countries which would balance the right to develop and the norm of sustainability.

I then discussed the importance of considering the needs of the current generation in intergenerational arguments. Singer has shown it is possible to end extreme poverty now through charity, however, I argue that as this has still not happened it is not a firm foundation for evaluating future conditions. It does however, illustrate how achievable a basic needs threshold would be. I outline Moellendorf's argument where he concludes that the importance of considering the current generation extends to the future, as issues of poverty may be amplified going forward, and the eradication of poverty sooner rather than later will have significant benefits for all future people. In contrast to this, I examine the argument from Rao that a more targeted approach to climate change mitigation is needed, especially if we want to include allowances for development. Rao argues that if the internal inequalities are addressed, this may make other states more willing to contribute to assisting the global poor, because they can have more certainty that this is where their assistance is going.

This leads to my final chapter where I discuss potential solutions and future leadership in climate change agreements. I argue that the concerns raised by Shue that there is no leadership in climate change has changed, and there are positive signs for future agreements. I do not believe that the concerns around concentrations of power need to be significant if there are representatives from both developed and developing countries. This leadership will be essential for maintaining the balance of the right to sustainable development and the norm of 
sustainability. I then discuss potential solutions, firstly by offering a critique of the current emissions trading scheme. Though I agree with Caney that there is not an inherent flaw in emissions trading schemes themselves, I argue that there are other solutions that may produce greater benefits overall. This primarily involves sharing of innovation and technology, not just financial assistance. This method would therefore allow for more development, as access to these resources is part of what is currently limiting fast development. It would also likely remedy some past emissions as the sates that currently have the innovation and resources are wealthy states that have often benefited from past emissions. Finally, I discuss the potential of combining outcome responsibility and the ability to pay principle in order to find a solution to obligation distribution. Outcome responsibility provides the direction of obligations, while the ability to pay ensures a fair and just distribution.

In this thesis I have shown it is possible to balance the right to develop and the norm of sustainability. It may even be possible to defend a stronger right to develop. However, I have argued for the limited right to sustainable development as the urgency and potential damage of climate change requires immediate action. Under the current context, a right to develop to the basic needs threshold can be balanced with the norm of sustainability to provide a just distribution of obligations between developed and developing states, and between and across generations. 


\section{References}

$\underline{\text { Books }}$

MOELLENDORF, David (2014), The Moral Challenge of Dangerous Climate Change: Values, Poverty, and Policy, Cambridge University Press.

POSNER, Eric, and WEISBACH, David (2010) Climate Change

Justice, Princeton University Press.

ROSER, Dominic, and SEIDEL, Christian (2016) Climate Justice: An Introduction, Routledge.

SHUE, Henry (2014), Climate Justice: Vulnerability and Protection, Oxford University Press.

SINGER, Peter (2010), The Life You Can Save: Acting now to end world poverty, The Text Publishing Company.

\section{Chapters in Books}

ALDRED, Jonathon (2016), "Emissions Trading Scheme in a 'NonIdeal' World" in Heyward, C and Roser, D (ed) Climate Justice in a Non-Ideal World, Oxford University Press, pp.148-168.

LIGHT, Andrew, and TARASKA, Gwynne (2016), "Enhancing Action on Short-Lived Climate Pollutants" in Heyward, C and Roser, D (ed) Climate Justice in a Non-Ideal World, Oxford University Press, pp.169-188.

MILLER, David (2011) “Taking Up the Slack? Responsibility and Justice in Situations of Partial Compliance" in Stemplowska, Z, and Knight, C (ed) Responsibility and Distributive Justice, Oxford University Press, pp.230-245. 
$\underline{\text { Journal Articles }}$

CANEY, Simon (2010), "Climate change and the duties of the advantaged" in Critical Review of International Social and Political Philosophy (volume 13, issue 1) pp. 203-228.

CANEY, Simon (2010)(b), "Markets, Morality and Climate Change: What, if anything, is Wrong with Emissions Trading?" in New Political Economy (volume 15, issue 2) pp. 197-224).

CANEY, Simon (2014), "Climate Change, intergenerational equity and the social discount rate" in Politics, Philosophy and Economics (volume 13, issue 4) pp. 320-342.

KNOPFE, Brigitte and KEJUN, Jiang (2017) "Germany and China take the lead" in Science (volume 358, issue 6363) pp. 569.

MILLER, David (2004), "Holding Nations Responsible" in Ethics (volume 114, issue 2) pp. 240-268.

MOELLENDORF, Darrel (2009), "Treaty Norms and Climate Change Mitigation" in Ethics and International Affairs (volume 23, issue 3, September 2009) pp. 247-265.

MOELLENDORF, Darrel (2009)(b), "Justice and the Assignment of the Intergenerational Costs of Climate Change" in Journal of Social Philosophy (volume 40, number 2, Summer 2009) pp. 204-224.

PICKERING, Jonathon, and BARRY, Christian (2012) "On the Concept of Climate Debt: Its moral and political value" in Critical Review of International Social and Political Philosophy (volume 15, issue 5) pp. 667-685.

RAO, Narasimha (2014) "International and intranational equity in sharing climate change mitigation burdens" in International Environmental Agreements (volume 14) pp. 129-146). 
SHUE, Henry (2011), "Face reality? After you! - a call for leadership on climate change" in Ethics and International Affairs (volume 25, number 1) pp. 17-26.

VALENTINI, Laura (2012), "Ideal vs non-ideal theory" in

Philosophy Compass (volume 7, issue 9, September 2012) pp. 654664.

$\underline{\text { Website }}$

CHRISAFIS, Angelique and VAUGHAN, Adam (2017) "France to ban sales of petrol and diesel cars by 2040"

<https://www.theguardian.com/business/2017/jul/06/france-banpetrol-diesel-cars-2040-emmanuel-macron-volvo> Accessed 24 January 2018). 